\title{
Activation of common signaling pathways during remodeling of the heart and the bladder
}

\author{
Ivonne Koeck ${ }^{1,2}$, Fiona C. Burkhard ${ }^{3}$, Katia Monastyrskaya ${ }^{1,3,}$ *
}

${ }^{1}$ Urology Research Laboratory, Department Clinical Research, University of Bern, Switzerland

${ }^{2}$ Graduate School for Cellular and Biomedical Sciences, University of Bern, Switzerland

${ }^{3}$ Department of Urology, University Hospital, Bern, Switzerland

\section{* Corresponding author:}

Katia Monastyrskaya,

Urology Research Laboratory,

Department Clinical Research,

University of Bern, Murtenstrasse 35,

CH-3008, Bern, Switzerland,

Tel: +4131 6328719;

Fax: + 41316320551

E-mail: monastyk@dkf.unibe.ch 


\section{ABSTRACT}

The heart and the urinary bladder are hollow muscular organs, which can be afflicted by pressure overload injury due to pathological conditions such as hypertension and bladder outlet obstruction. This increased outflow resistance induces hypertrophy, marked by dramatic changes in the organs' phenotype and function. The end result in both the heart and the bladder can be acute organ failure due to advanced fibrosis and the subsequent loss of contractility. There is emerging evidence that microRNAs (miRNAs) play an important role in the pathogenesis of heart failure and bladder dysfunction. MiRNAs are endogenous non-coding single-stranded RNAs, which regulate gene expression and control adaptive and maladaptive organ remodeling processes. This Review summarizes the current knowledge of molecular alterations in the heart and the bladder and highlights common signaling pathways and regulatory events. The miRNA expression analysis and experimental target validation done in the heart provide a valuable source of information for investigators working on the bladder and other organs undergoing the process of fibrotic remodeling. Aberrantly expressed miRNA are amendable to pharmacological manipulation, offering an opportunity for development of new therapies for cardiac and bladder hypertrophy and failure.

\section{KEYWORDS}

Fibrosis, bladder, heart, miRNA, pressure overload, obstruction, signaling, gene expression 


\section{Introduction}

Although the heart and the urinary bladder serve distinct functions in the body, both are designed to undergo repeated cycles of filling and emptying, albeit with remarkably different kinetics. The heart ensures a constant supply of blood to all other organs, contracting and relaxing continuously from early embryogenesis until death. The bladder on the other hand stores urine as it is being produced by the kidneys and empties when an appropriate opportunity arises, usually once every few hours. Contraction and relaxation of the heart and the bladder are governed by different mechanisms. However when there is a resistance interfering with liquid outflow, their respective contractile units, cardiomyocytes and bladder smooth muscle cells (SMCs), can be subjected to pressure and volume overload.

Notwithstanding the structural and functional differences between the bladder and the heart, both organs respond to the pathological pressure overload by hypertrophy and fibrotic remodeling leading to the loss of contractility $[1,2]$. Due to the immediate life-threatening nature of these processes in the heart, the wealth of experimental and clinical data far surpasses that of the bladder. Although not all observations are immediately transferrable from one organ to the other, there are striking parallels in the cellular and molecular mechanisms, which we will discuss in this Review. We will regard the processes, occurring during pressure overload-induced organ remodeling in the heart and the bladder in the context of the role of miRNAs, important epigenetic regulators of stress signaling pathways.

\section{Dysfunction of the heart and the bladder caused by sustained pressure overload}

Normally, the heart responds to an increase in blood flow by adjusting the stroke volume and rate. Increased filling pressure and volume intensify the stretching force on the myocardium leading to a pressure overload. Because the adult mammalian myocardium has negligible regenerative capacity, it responds to this mechanical stress by producing additional sarcomeres leading to an increase in myocyte size. In the heart volume overload occurring due to mitral regurgitation or arteriovenous fistulas causes increased diastolic stress and results in eccentric hypertrophy. The heart is enlarged, but the wall is thin with big cavities; cardiomyocytes are elongated due to the serial insertion of new sarcomeres [3]. In contrast, hypertension, aortic stenosis and other stimuli, resulting in pressure overload, induce parallel insertion of sarcomeres and an increase in myocyte width, characteristic of concentric hypertrophy [4]. Both pressure overload and stretching of the cardiomyocytes activate growth signaling pathways, which lead to organ remodeling [5]. Cardiac hypertrophy can be physiological, when it is induced by prolonged exercise or during pregnancy, or pathological, when it develops in response to hypertension, aortic stenosis, heart valve insufficiency or myocardial infarction [6]. While both types of hypertrophy provoke increased myocardial mass, pathological hypertrophy is accompanied by extensive fibrosis, cardiac dysfunction and ultimately heart failure. Physiological hypertrophy, in contrast, is characterized by normal cardiac structure and function, and is reversible [7]. Not surprisingly, in each type of cardiac hypertrophy involve different signaling pathways [8]. Pressure overload-induced cardiac hypertrophy initially is an adaptive 
response aiming to maintain output. However, when the underlying cause is not eliminated, an extensive organ remodeling program is initiated, resulting in increased myocardial stiffness due to fibrosis, diastolic dysfunction and eventually ventricular dilation and combined diastolic and systolic heart failure [9]. The pathological mechanisms of an isolated volume overload marked by eccentric left ventricular remodeling and dysfunction are less clearly defined, although many parallels are emerging [10]. It has been shown that chronic volume overload is a stimulus for myocardial fibrosis in human patients [11] and animal models [12], with similar signaling pathways activated in both in concentric and eccentric hypertrophy [12].

The lower urinary tract (LUT) comprises the bladder and urethra. The bladder is a musculomembranous hollow organ, which stores and expulses urine. Prerequisite for normal storage and voiding is a coordinated interaction between the muscle components of the bladder wall (detrusor) and its outlet (urethra and sphincter). During the filling phase the bladder wall maintains a certain degree of tension, which is caused by myogenic contractile activity, while detrusor pressure remains low without detectable muscle contractions [13]. Activation of the sphincter in the absence of detrusor contractions during the filling phase preserves continence [14].

When this process is impaired, lower urinary tract dysfunction (LUTD) with the symptoms of urgency, frequency and incomplete emptying can occur. LUTD is caused by various pathologies including neurologic disorders and bladder outlet obstruction (BOO) [15]. BOO caused by benign prostatic hyperplasia $(\mathrm{BPH})$, which affects the majority of men as they age [16], or urethral strictures, leads to an increased resistance during voiding and is more commonly observed in men than in women [17]. BOO necessitates an increased intravesical pressure to void completely and results in profound structural and functional changes in the bladder wall, bladder hypertrophy, which resemble those of concentric myocardial hypertrophy. The increase in wall thickness corresponds to the severity of obstruction [18], with a significant correlation between the two observed in men with $\mathrm{BPH}$ [19]. In contrast, volume overload injury in the bladder of human patients is a rare occurrence, and is usually prevented by catheterization [20]. Bladder hypertrophy is characterized by changes in the expression profile of SM contractile and signaling proteins, modification of extracellular matrix (ECM) proteins, and an increase in bladder innervation [21, 22]. Although relief of obstruction is a traditional form of therapy for this disorder, many storage and voiding symptoms, including urgency, frequency and incomplete emptying, persist after surgery, indicating that timing of the surgical intervention may be critical for complete recovery of bladder function. As bladder outlet obstruction progresses from inflammation to hypertrophy to fibrosis [23], early identification of structural changes can guide therapeutic decisions that might prevent further damage to the bladder and optimize the timing of treatment. Reliable markers of bladder function are urgently needed in order not to surpass the "point of no return", leading to bladder decompensation/failure.

\section{Regulatory miRNAs and their impact in disease}

Since their discovery in the early 1990s [24], miRNAs have emerged as central regulators of many biological processes, including proliferation, differentiation and cell death [25]. MiRNAs are 
endogenous non-coding single-stranded RNAs of approximately 22 nucleotides which regulate gene expression by post-transcriptional mechanisms upon sequence-specific binding to the 3 ' untranslated regions (3' UTRs) [25, 26] or, occasionally, the 5'UTRs [27, 28] or coding regions [2931] of their mRNA targets. The short "seed" sequences (nucleotides 2-8) at the 5' ends of miRNAs are most critical and often sufficient for target selection. MiRNAs exhibit imperfect complementarity with mRNAs, allowing them to regulate multiple genes and thus complicating efforts to predict and functionally validate their targets [32]. Each miRNA target is regulated in the range of a 2-fold change, therefore the additive effect of simultaneous regulation of a large number of transcripts is believed to bring about strong phenotypic effects [33]. The details of miRNA synthesis are well characterized and extensively reviewed elsewhere [34-36].

MiRNAs are produced in a wide range of species, with more than 1000 encoded by the human genome [37]. Changes in their expression profiles, occurring concomitant with emerging pathologies, have led to the notion that in addition to their developmental function, they might influence the responses of already differentiated tissues to physiologic and pathophysiologic stress [38]. This suggests a role of miRNAs in disease states, and indeed dysregulation of their synthesis contributes to fibrotic diseases of the lung, liver and the heart [39-41]. The first miRNA profiling of a LUTD was performed for bladder pain syndrome (BPS) in our laboratory. We identified several miRNAs, which affect the expression of signaling and adhesion molecules known to be relevant for the pathogenesis of bladder pain [42], suggesting a regulatory role of miRNAs. Follow-up experiments established the role of miRNAs in the regulation of urothelial permeability [43] and bladder SMC proliferation and morphology [44]. More recent studies implicated miRNAs in the regulation of bladder contractility $[45,46]$.

\section{The cellular effectors of cardiac and bladder fibrosis}

Although cell types comprising the heart and the bladder are different, their response to pathologic pressure bears a lot of similarity. The contractile cells of both organs, cardiomyocytes and detrusor SMCs (dSMC), are capable of a considerable morphologic and proliferative plasticity. Initially, both cardiomyocytes and dSMCs undergo an increase in size as a result of increased synthesis and incorporation of contractile elements. In the heart, this is associated with structural remodeling including changes in fibrillar collagen network and angiogenesis [8]. Chronic pressure overload, unlike physiologic hypertrophy, may then activate pro-fibrotic pathways leading to cell death (apoptosis, necrosis) and the replacement of the lost myocytes with excessive collagen. Fibrosis and reduced capillary density leads to myocardial ischemia, further exacerbating the damage and contributing to the transition from hypertrophy to heart failure [47]. Several cell types are implicated in the heart fibrosis, either directly (collagen-producing fibroblasts and myofibroblasts) or by secreting fibrogenic mediators (macrophages, mast cells, lymphocytes, cardiomyocytes and vascular cells). 
Myofibroblasts combine the features of SMCs (expression of SM $\alpha$-actin) with excessive extracellular matrix protein production, and myofibroblast accumulation has been reported in the pressure overloaded myocardium. Activation of resident cardiac fibroblasts by fibrogenic mediators such as transforming growth factor beta (TGF- $\beta$ ) is probably the most important source of myofibroblasts in the fibrotic heart [48], although their trans-differentiation from pericytes, endothelial cells and circulating progenitors has been described [49]. Immune cells, most notably monocytes and macrophages are increasingly implicated in the regulation of the fibrotic response, both during its initiation (M1 macrophages induced by IFN- $\gamma$ alone or in combination with TNF- $\alpha$ and GM-CSF) and its resolution and the subsequent reduction of inflammation (M2 macrophages, induced by IL-4 or IL-13) [50]. Similarly, mast cells are instrumental in the regulation of inflammatory and fibrotic processes in the heart. They release a vast array of fibrogenic mediators, including histamine, TNF- $\alpha$, TGF- $\beta$, IL-4, PDGFs and FGFs, and increased density of mast cells has been observed in pressure overloaded hearts [51].

Unlike terminally differentiated cardiomyocytes, dSMCs retain the ability to undergo a switch from contractile to proliferative phenotypes. Both hypertrophy and hyperplasia of dSMCs has been reported during remodeling of obstructed bladders [52]. Contractile properties of dSMCs are gradually impaired during BOO-induced remodeling, accompanied by a shift in myosin heavy chain mRNA isoform expression towards the embryonic/proliferative phenotype [53]. Myofibroblasts, differentiating from resident mesenchymal cells of the bladder serosa, have also been postulated to play a role in the development of detrusor overactivity during experimental outflow obstruction [54]. Similar to their function in the diseased heart, myofibroblasts could be a source of extracellular matrix produced during BOO-induced fibrosis. Experimental partial $\mathrm{BOO}$ ( $\mathrm{pBOO}$ ) in animal models progresses through several stages from inflammation to fibrosis [23]. Acute inflammation is characterized by release of cytokines such as IL-1, TNF- $\alpha$ and IL-6 [55], prostaglandines, histamine secretion, vasodilation and increased vascular permeability [56]. These mediators cause urothelial irritation, which is responsible for the symptoms of urgency, dysuria and increased frequency. Cytokines and growth factors have been shown to cause inflammation and bladder remodeling after pBOO. A recent study demonstrated that the inflammatory cytokine IL-1 $\beta$ is essential in inducing bladder remodeling and deterioration of bladder function in pBOO [57].

\section{Role of miRNAs in the signaling pathways activated by sustained pressure overload in the heart and the bladder}

The activation and phenotypic modification of contractile and interstitial cells described above is accompanied by changes in gene expression reflected in differential activation of intracellular signaling pathways. In the heart, comparative studies between physiological and pathological hypertrophy revealed activation of pathways specific for each condition. In reversible, physiological cardiac hypertrophy, major activated pathways are IGF1-phosphoinositide 3-kinase (PIK3, (p110 $\alpha$ )Akt pathway [58], gp130/JAK/STAT pathway [59], thyroid hormone signaling [60] and heat shock transcription factor (HSF1) [61]. In contrast, pathological cardiac hypertrophy is induced by Gaq 
signaling activated by GPCRs of angiotensin II (Ang II) [62], endothelin ET1 [63] and catecholamines [64] and eventually converging with intracellular $\mathrm{Ca}^{2+} /$ calcineurin [65], protein kinase C (PKC) and PTEN-PIK3 $\gamma$ pathways [66].

To date, the function of miRNA in stress-responsive pathways has predominantly been studied in the context of cardiovascular disease, and less well described in the bladder. Nevertheless, activation of the main intracellular signaling pathways, relevant for hypertrophy, fibrosis and decompensation such as $\mathrm{Ca}^{2+} /$ calcineurin signaling, TGF- $\beta$, Wnt/Frizzled/ $\beta$-catenin signaling and ECM remodeling have been reported in obstructed bladders, and some similarities in miRNA expression profiles are beginning to emerge. Here, we summarize the main processes involved in pressure overload-induced cardiac hypertrophy and decompensation, and define their role in BOOinduced bladder dysfunction.

\section{1. $\mathrm{Ca}^{2+} /$ calcineurin/Nuclear Factor of Activated $T$ cells (NFAT) pathway}

Contractile function and cell growth of both cardiomyocytes and dSMCs are controlled by calcium. Calcium is an important second messenger for $G$ protein-coupled receptors and biomechanical stress and its downstream effectors calmodulin and calcineurin transmit the information encoded in the fluctuations of intracellular $\mathrm{Ca}^{2+}$ concentration into cellular processes. The $\mathrm{Ca}^{2+} /$ calcineurin/NFAT pathway, activated by sustained elevation of intracellular $\mathrm{Ca}^{2+}$ levels, plays a central role in the development of cardiac hypertrophy and failure [67]. Phosphorylated NFAT proteins reside in the cytoplasm and are dephosphorylated by activated calcineurin. Their subsequent translocation to the nucleus initiates a muscle hypertrophy gene expression program [68]. Calcineurin activity is increased in hypertrophied and failing human hearts [69], animal models of aortic constriction [70] and transgenic animals, developing cardiac hypertrophy upon overexpression of an activated form of this enzyme [67].

There is evidence that muscle-specific miRNAs miR-1 and miR-133, which are clustered on the same chromosomal locus [71, 72], are involved in the regulation of cardiac hypertrophy. Expression levels of miR-1 increase during differentiation [73], making it the most abundant miRNA in the adult heart [74]. The data indicating that miRNAs affect the $\mathrm{Ca}^{2+}$-induced gene expression are just emerging: in the heart, miR-1 inhibits the translation of calmodulin-encoding mRNAs and downregulates calcium-calmodulin signaling through calcineurin to NFAT. MiR-1 also negatively regulates the expression of myocyte enhancer factor MEF2a and GATA4, key transcription factors mediating calcium-dependent changes in gene expression [75]. MiR-133a has been implicated in targeting NFATc4, reducing its levels and attenuating alpha-adrenergic receptor agonist-induced cardiomyocyte hypertrophy [76]. A suppression of miR-133 induces hypertrophy in vivo and in vitro by enhancing calcineurin expression [77], whereas its overexpression produces the opposite effect [72].

Studies in mice and humans showed that an overexpression of pre-miR-212 or pre-miR-132 leads to an enlargement of cardiomyocytes and development of cardiac hypertrophy. Mice without miR- 
212/132 were protected from cardiac hypertrophy, and the pharmacological knock-down of miR-132 by antagomir injection effectively blocked cardiac hypertrophy [78]. Furthermore, this study demonstrated that the miR-212/132 family targets and negatively regulates the expression of FoxO3 transcription factor, which is an anti-hypertrophic and pro-autophagic factor in cardiomyocytes. MiR212/132 overexpression and FoxO3 down-regulation result in a hyperactivation of the prohypertropic calcineurin/NFAT signaling pathway [78]. Interestingly, it has also been shown that miR1 expression in cardiomyocytes is regulated by the Akt- FoxO3 pathway [79] and miR-1 levels were down-regulated in miR-212/132 overexpressing transgenic hearts [78].

Both the $\alpha$ - and $\beta$-isoforms of the calcineurin catalytic subunit are direct targets of miRNA miR- 499 . MiR-499 inhibits cardiomyocyte apoptosis through the suppression of calcineurin-mediated dephosphorylation of dynamin-related protein-1 (Drp1), thereby decreasing Drp1 accumulation in mitochondria and Drp1-mediated activation of the mitochondrial fission program. It has been suggested that modulation of miR-499 levels may provide a therapeutic approach for treating myocardial infarction and heart fibrosis [80].

MiR-22 is essential for hypertrophic cardiac growth in response to stress. MiR-22-null hearts blunted cardiac hypertrophy and cardiac remodeling in response to 2 independent stressors: isoproterenol infusion and an activated calcineurin transgene. Loss of miR-22 sensitized mice to the development of dilated cardiomyopathy under stress conditions. Sirt1 and specific histone deacetylase HDAC4, which normally binds to and represses cardiac-specific transcription factors MEF2c and MEF2d were identified as miR-22 targets in the heart [81].

Similarly, miR-23a expression was up-regulated upon prolonged treatment with the isoproterenol and aldosterone. Knockdown of miR-23a could attenuate the ensuing hypertrophy, suggesting that miR-23a is able to convey the hypertrophic signal. The expression levels of miR-23a were controlled by $\mathrm{Ca}^{2+} /$ calcineurin via NFATc3 [82].

$\mathrm{miR}-199 \mathrm{~b}$ is another direct calcineurin/NFAT target gene which increases expression in mouse and human heart failure, and targets the nuclear NFAT kinase dual-specificity tyrosine-(Y)phosphorylation regulated kinase 1a (Dyrk1a), constituting a pathogenic feed-forward mechanism that affects calcineurin-responsive gene expression. Inhibition of miR-199b by a specific antagomir normalized Dyrk1a expression, reduced nuclear NFAT activity and caused marked inhibition and even reversal of hypertrophy and fibrosis [83].

The involvement of calcineurin / NFAT signaling in bladder hypertrophy is just beginning to emerge: mRNAs for all four known calcineurin-responsive NFAT isoforms were detected in urothelium and SMCs, and experimentally-induced $\mathrm{pBOO}$ in mice was shown to activate the calcineurin/NFAT pathway [84]. Treatment of pBOO mice with cyclosporine A (CsA), an inhibitor of calcineurin, significantly reduced hypertrophy secondary to obstruction and improved bladder performance [84]. In agreement with activation of calcineurin/NFAT signaling in obstructed bladders, a recent study has demonstrated an up-regulation of miR-212/132 cluster in pBOO animals [85]. The putative 
binding sites in the miR-132/212 promoter were compared with transcription factors predicted to be active in the obstruction model, and Creb and Ahr were implicated in miR-212/132 induction. Additionally, serum stimulation and protein kinase $C$ activation induced miR-212/132 expression in human detrusor cells. MeCP2, Pnkd and Ache were validated as direct targets of miR-132 and miR212 in the detrusor, suggesting that this miRNA cluster influences gene expression and limits cell growth [85].

\subsection{TGF- $\beta$ in hypertrophy and fibrosis}

TGF- $\beta$ is a key player in wound healing, fibrosis and negative regulation of inflammation, and its levels are increased in the majority of fibrotic diseases [86, 87]. Its co-factors, the activating and inhibiting Smads, transmit the signal to the nucleus, resulting in activation of target genes, including contractile and ECM proteins. Non-canonical, Smad-independent signaling via TGF- $\beta$ occurs via direct activation of TGF- $\beta$-activated kinase TAK1, and plays a pivotal role in pathological cardiac response to sustained pressure overload [88]. Importantly, bone morphogenetic protein BMP7, a negative regulator of TGF- $\beta$ signaling during fibrosis, is selectively suppressed by activated TAK 1 in TGF- $\beta$-stimulated myocytes. TAK1 can also be activated by inflammatory cytokines IL- 1 and TNF- $\alpha$, actively released during cardiac and bladder obstruction [89], and might represent an important cross-talk point between different fibrogenic pathways.

In addition to cardiomyocytes, the myocardium contains cardiac fibroblasts, endothelial and smooth muscle cells [90]. TGF- $\beta$ not only activates cardiomyocytes, resulting in cell hypertrophy and production of fibrogenic mediators, but also has a profound and consistent effect on cardiac fibroblasts, which are probably its main effectors in the heart [91]. Cardiac fibroblasts, which derive from mesenchymal cells, are able to differentiate into myofibroblasts and produce vast quantities of ECM proteins [92]. Activated myofibroblasts are found in the myocardium during cardiac injury [93]. Accumulation of ECM proteins is the reason for stiffness of the myocardium and leads to impaired heart function. TGF- $\beta 1$ induces SM differentiation via activation of $p 38$ MAPK, which is in turn required for activation of the SMC marker gene promoters. TGF- $\beta$ also activates Rho $A$ and its downstream target protein kinase $\mathrm{N} 1$ (PKN). Overexpression of active PKN increases the transcriptional activity of the promoters that control expression of SM $\alpha$-actin, SM-myosin heavy chain, and SM22- $\alpha$, and the activities of serum-response factor (SRF), GATA, and MEF2dependent enhancer-reporters [94]. This enables TGF- $\beta$ and its downstream target connective tissue growth factor (CTGF) to stimulate differentiation of myofibroblasts and enhance collagen deposition in the pressure-overloaded heart.

Similar to the heart, TGF- $\beta 1$ is increased in obstructed bladder undergoing hypertrophy [23] and collagen deposition [95]. Progressive accumulation of ECM, characteristic of the fibrotic bladder, leads to reduced contractility and impaired micturition during the final decompensated/fibrotic stage. CTGF increases as a response to stress and enhances the stretch-mediated collagen deposition in 
the bladder, whereas TGF- $\beta$ increases smooth muscle growth and differentiation, both resulting in the hypertrophy during the early stages of obstruction [96].

In addition to influencing mRNA expression, TGF- $\beta$ induces expression of several miRNAs involved in fibrosis, including miR-192, and miR-491-5p. The role of miR-192, also up-regulated in BPS [97], in promoting fibrosis is best defined in the kidney [98], where it may be a critical downstream mediator of TGF- $\beta /$ Smad3 signaling for the development of renal fibrosis [99]. CTGF also increases miR-192 expression [100], whereas vascular endothelial growth factor (VEGF), a key promoter of angiogenesis, suppresses epithelial-mesenchymal transition (EMT) by inhibiting Smad3 and miR192, whose expression is Smad3-dependent [101]. In addition to miR-192, Smad3 mediates renal and cardiac fibrosis by up-regulating miR-21 and down-regulating the miR-29 and miR-200 families [87]. MiR-21 is especially important in the heart, where it is induced during hypertrophy [86], and has been postulated to target inhibitory Smad7, thus enhancing TGF- $\beta$ signaling. MiR-21, which is increased in cardiac fibroblasts during stress, represses Sprouty homolog 1 (Spyr1), a negative regulator of the extracellular signal-regulated kinase/mitogen-activated protein (ERK-MAP) kinase signaling pathway [102]. Spyr1 is known to induce secretion of fibroblast growth factor and fibroblast survival, leading to increased interstitial fibrosis. Silencing miR-21 using an antagomir reduced cardiac ERK-MAP kinase activity and inhibited cardiac fibrosis in pressure-overload mouse models [102].

Overexpression of hepatocyte growth factor (HGF) reduces TGF- $\beta 1$ production and activity in cardiac fibroblast cultures and animal models of cardiomyopathy [103]. HGF is a multi-potent endogenous repair factor secreted primarily by mesenchymal cells, it enhances normal tissue regeneration and inhibits fibrotic remodeling by inhibiting myofibroblast proliferation. TGF- $\beta 1$ suppresses HGF expression via miR-199a-3p [104]. HGF also induces anti-fibrotic miR-29 expression, while TGF- $\beta$ stimulation leads to a reduction in miR-29 expression and de-repression of collagen synthesis. Stimulation with HGF was associated with highly elevated miR-29 levels and markedly repressed synthesis of collagen-I and -IV [105].

MiRNAs 143/145 (miR-143/145) are highly expressed in adult SMC lineages and mediate, in part, the expression of several SMC contractile genes. They modulate cytoskeletal dynamics and promote SMC migration following an injury [106]. TGF- $\beta 1$ stimulates miR-143/145 expression in a dose- and time-dependent manner. The effect of TGF- $\beta 1$ on miR-143/145 is mediated by $\mathrm{p} 38$ MAPK and is dependent on the myocardin and serum response factor transcriptional switch as well as Smad4 [107]. Pre-miR-145 promotes, whereas an anti-miR-145 partially blocks, TGF- $\beta 1$-induced SMC differentiation [107].

MiR-199a-5p is another miRNA, strongly up-regulated by TGF- $\beta$ [108]. It is particularly important in cells of mesenchymal origin. MiR-199a-5p is highly expressed in bladder smooth muscle [43], as well as cardiomyocytes. In cardiomyocytes it down-regulates hypoxia-inducible factor 1 alpha (HIF$1 \alpha$ ) and sirtuin 1 [109], and promotes cardiomyocyte hypertrophy [110]. MiR-199a-5p targets WNT2 [111], and regulates multiple cytoskeletal remodeling pathways [43, 44]. Its overexpression in the 
dSMCs significantly increased cell size and up-regulated SM-specific contractile proteins. These changes were mediated by up-regulation of SM-specific transcriptional activator myocardin at mRNA and protein levels. Myocardin-related transcription factor (MRTF-A) downstream targets Id3 and MYL9 were also induced. Up-regulation of myocardin was accompanied by down-regulation of WNT-dependent inhibitory Krüppel-like transcription factor 4 (KLF4) in miR-199a-5p overexpressing cells. In contrast, KLF4 was induced in antimiR-expressing cells following the activation of WNT2 signaling, leading to repression of myocardin-dependent genes. MiR-199a-5p plays a critical role in the WNT2-mediated regulation of proliferative and differentiation processes in the smooth muscle and may act as a key modulator of smooth muscle hypertrophy, relevant for organ remodeling (Figure 1) [44].

Early cardiac marker genes, such as cardiac-specific homeobox (Csx/Nkx2.5), myocardin, homeodomain only protein, GATA4, and MEF2C, are thought to participate in cardiomyocyte differentiation and contribute to cardiac hypertrophy in animal models. Myocardin, a potent transcriptional coactivator of SM and cardiac genes, is up-regulated in the myocardium in animal models and human end-stage heart failure. Up-regulation of myocardin expression in the heart has been linked to hypertrophic cardiomyopathy in human patients [112]. Silencing $M Y O C D$ gene by a short hairpin RNA in a mouse model of heart failure normalized the levels of myocardin and several fetal genes, including SMC genes and attenuated cardiac muscle dysfunction [113]. Interestingly, hypoxia has been shown to induce both MYOCD gene expression and cardiomyocyte hypertrophy [114], although the exact nature of this link is not clear. Taking into account that miR-199a-5p is also up-regulated by hypoxia [115], and in view of its ability to indirectly induce the MYOCD gene which we observed in SMCs [44], it might act as an important factor promoting increased, pathological myocardin synthesis in cardiovascular diseases. A recent study has demonstrated that KLF4 attenuates isoproterenol-induced cardiac hypertrophy by inhibiting myocardin expression and activity [116], therefore a down-regulation of WNT-dependent KLF4 protein by miR-199a-5p [44] could have an opposite effect, ultimately up-regulating myocardin and causing heart hypertrophy.

In contrast to the examples above, TGF- $\beta$ is also capable of repressing the synthesis of several miRNAs, such as miR-29, miR-30 and miR-133 which have anti-fibrotic properties [117]. In the heart, the miR-29 family targets mRNAs that encode proteins involved in fibrosis, including multiple collagens, fibrillins, and elastin. Down-regulation of miR-29 de-represses the expression of these mRNAs and enhances fibrotic response [118]. MiR-133a1/a2, expressed in cardiomyocytes, are down-regulated during cardiac injury. MiR-133a-1 and miR-133a-2 are identical, muscle-specific miRNAs that are regulated during muscle development by the SRF transcription factor. Their deletion enhanced ectopic expression of smooth muscle genes in the heart and aberrant cardiomyocyte proliferation by up-regulating SRF (negative feedback loop) and cyclin D2 [119].

In the bladder, a recent study addressed the role of miR-133 during BOO-induced TGF- $\beta$-mediated hypertrophic and fibrotic response. Similar to the diseased heart, miR-133 was down-regulated during bladder remodeling in the rat and stimulation of the bladder SMCs with exogenous TGF- $\beta 1$ resulted in a dose-dependent decrease of miR-133a/b levels. Transfection of miR-133 mimics 
attenuated TGF- $\beta 1$-induced SM $\alpha$-actin, ECM proteins and fibrotic growth factor expression, and upregulated high molecular weight caldesmon expression in the bladder SMCs. Downregulation of p-Smad3, not p-Smad2 by miR-133 was also detected. Additionally, miR-133 overexpression suppressed TGF- $\beta 1$-induced SMC hypertrophy and proliferation by directly targeting CTGF. In the obstructed bladder, miR-133 modulates TGF- $\beta 1$-induced SMC phenotypic changes by downregulating CTGF through the TGF- $\beta$-Smad3 signaling pathway [120]. Muscle-specific miR-133 clusters together with miR-1, which has been implicated in regulation of bladder overactivity by reducing the expression levels of connexin 43 (GJA1), a major gap junction protein in the detrusor, in a myocardin-dependent manner [121]. Myocardin decreased GJA1 expression through miR-1 up-regulation, thereby contributing to the maintenance of normal sensitivity and increase in bladder capacity.

In the bladder miR-29 is negatively regulated by TGF- $\beta$ and plays a role in remodeling of the extracellular matrix during BOO. MiR-29 was repressed in an animal model of pBOO leading to matrix remodeling and increased bladder stiffness [46]. c-Myc, NF-kappaB and Smad3 repressed miR-29, causing increased levels of miR-29 target mRNAs tropoelastin, the matricellular protein Sparc and collagen IV. Thus, TGF- $\beta$ signaling via its downstream effectors reduced miR-29 in BOO, and the resulting decline in miR-29 contributed to matrix remodeling and altered passive mechanical properties of the detrusor [46].

\subsection{Renin-angiotensin system}

The renin-angiotensin system (RAS) is emerging as one of the key players in hypertrophy and fibrosis, in both the heart and the bladder [122, 123]. Angiotensin II (Ang II) is a peptide that regulates blood pressure, vascular tone and sodium homeostasis. Most of its effects, including contractile increase, are mediated via AT1 and less well described AT2 Gaq protein-coupled receptors and $\mathrm{Ca}^{2+}$ release from the sarcoplasmic reticulum. The heart contains a local RAS system, which is activated by pressure overload [124], and blocking Ang II formation with angiotensin converting enzyme inhibitors attenuates pressure overload-mediated heart hypertrophy in animals and humans [125]. Ang II stimulates AT1 receptors which are expressed in the bladder in both smooth muscle and urothelial cells, and Ang II-mediated detrusor contractility has been reported [126]. Application of AT1 receptor antagonists in animal models of pBOO significantly reduced organ hypertrophy and collagen deposition, implicating activation of RAS in bladder fibrosis [127]. It is possible that the pro-fibrotic activity of Ang II is mediated by downstream activation of TGF- $\beta$ signaling and subsequent collagen accumulation [128]. These observations were further confirmed by the fact that inhibitory Smad7 prevented Ang II-induced cardiac fibrosis via mechanisms involving the Sp1-TGF- $\beta /$ Smad-NF-kB-miR-29 regulatory network [128].

Many miRNA that affect activated Ang II-AT1 signaling act on TGF- $\beta$ or $\mathrm{Ca}^{2+}$ pathways. A global miRNA array analysis of Ang II-mediated miRNA regulation in cells overexpressing the AT1 receptor focused on separating the role of Gaq/11-dependent and -independent pathways. Five 
miRNAs (miR-29b, -129-3p, -132, -132* and -212) were induced by Ang II, and their up-regulation was blocked following Gaq/11 and MEK1 inhibition [129]. Chronic Ang II infusion induced an upregulation of the hypertrophic miR-132 and miR-212 [130].

There is evidence of a cross-talk between interleukin-6 (IL-6), which plays a role in cardiac hypertrophy and fibrosis, and Ang II. Binding of Ang II to AT-1 receptors stimulates IL-6 secretion [131]. Expression of both IL-6 and its signal transducer gp130 has been reported in cardiomyocytes and cardiac fibroblasts [132] and IL-6 concentration in cultured cardiomyocytes was decreased following application of the AT-1 receptor antagonist, strengthening the link between the two signaling systems [132]. These results suggest that IL-6 contributes significantly to cardiomyocyte hypertrophy by an autocrine pathway and to fibroblast proliferation by a paracrine pathway and that these effects could be mediated by Ang II.

AT1 receptor is a target for miR-155 [133], a miRNA important both in regulation of immune response and cardiac hypertrophy. MiR-155 is expressed in cardiomyocytes, where it represses the expression and function of MEF2A and Jarid 2. In mouse models of cardiac hypertrophy, loss of miR-155 suppressed cardiac hypertrophy and cardiac remodeling in response to two independent pathological stressors, transverse aortic restriction and an activated calcineurin transgene and prevented the progress of heart failure thus substantially extending the survival of calcineurin transgenic mice [134].

\subsection{Hypoxia}

As obstruction- or pressure overload-induced bladder and heart remodeling progresses from activated contractility to compensatory hypertrophy, the intrinsic demands for oxygen steadily grow, and cause up-regulation of HIF-1 $\alpha$ (hypoxia inducible factor-1 $\alpha$ ) [135, 136]. HIF-1 $\alpha$ functions as a master regulator of $\mathrm{O}_{2}$ homeostasis by controlling $\mathrm{O}_{2}$ delivery and utilization. Heart tissue hypoxia or ischemia resulting from arterial stenosis induces HIF-1 $\alpha$ activity, which is required for the production of angiogenic growth factors that stimulate vascular remodeling to increase blood flow through collateral vessels [135]. Interestingly, volume overload, which is less pro-fibrotic than pressure overload in the heart [137] is characterized by reduced propensity for ischemia and linked to a reduced expression of a novel cytokine resistin [138], which interacts with the profibrotic factors.

As obstruction progresses in the bladder, hypoxia develops in the detrusor smooth muscle, marked by an elevation of inducible nitric oxide synthase and VEGF mRNA levels and a decrease in the intercontraction interval [139]. Similarly, hypoxia-induced endogenous up-regulation of VEGF was shown to accelerate growth of the bladder by detrusor and urothelium hypertrophy and hyperplasia [140]. HIF-1 $\alpha$ activation in bladder outlet obstruction involves mechanisms beyond the accumulation of HIF-1a protein and results in a switch of the energetic support of contraction to anaerobic glycolysis characterized by increased expression of glucose transporters and glycolytic enzymes combined with mitochondrial remodeling. Together, these changes uphold contractility when mitochondrial respiration is limited [141]. 
Hypoxia has been shown to influence the expression of many miRNAs via a plethora of signaling pathways. In vascular smooth cells, hypoxia induces SMC proliferation by increasing the expression levels of miRNA-21, thus regulating the smooth muscle phenotype. Hypoxia-induced plateletderived growth factor (PDGF) has been shown to induce the transcription of miRNA-221 and miRNA-222, leading to the phenotypic switching in vascular smooth muscle cells [142]. Overexpression of these miRNAs causes down-regulation of myocardin, instrumental in maintaining the contractile phenotype of smooth muscle. The induction of miRNA-210 and -373 is dependent on hypoxia-induced factor HIF-1 $\alpha$. [143]. On the other hand, HIF-1 $\alpha$ is itself a target of miR-199a-5p, predominantly expressed in cardiomyocytes, and playing a role in the regulation of cardiac hypertrophy [110]. Because miR-199-5p is increased by cardiac hypoxia following activation of DNM3os, a noncoding transcript that harbors the miRNA cluster miR-199a 214 [115], it forms a negative feed-back loop controlling the levels of HIF-1 $\alpha$. A spectrum of miRNAs, including miR-23, $24,-26,-27,-103,-107,-181,-210$, and -213 is induced in response to low oxygen, at least some via a HIF-dependent mechanism [144]. Among these, hypoxia-induced miR-210 is a masterregulator and marker of hypoxic response [145], and has an anti-apoptotic effect on SMCs [146].

\subsection{Phosphoinositide 3-kinase (PI3K) signaling in pathologic hypertrophy}

Phosphoinositide 3-kinase (PI3K), Akt and mammalian target of rapamycin (mTOR) pathway is important for regulation of cardiomyocyte size, survival, angiogenesis and inflammation in cardiac hypertrophy [147]. In contrast to the receptor tyrosine kinase-coupled p110 $\alpha$ isoform of PI3K, involved in signal transduction during physiological heart growth, GPCR-coupled p110 $\mathrm{PI} 3 \mathrm{~K}$ is prominent in heart pathology. p110 $\mathrm{PI} 3 \mathrm{~K}$ does not affect cardiomyocyte size, but is a negative regulator of heart muscle contractility [66]. Activated PI3K creates phospholipid binding sites for a serine/threonine kinase Akt on the cell membrane. Akt mediates growth signals through inactivation and phosphorylation of pro-apoptotic proteins [148]. Phosphatase and tensin homologue on chromosome ten (PTEN) is a negative regulator of Akt. PTEN is targeted by miR-21, a pro-fibrotic miRNA discussed earlier, and modulation of miR-21 regulated expression of matrix metalloprotease-2 (MMP-2) via a PTEN pathway [149]. Similarly, reduction of miR-22 levels attenuated an Ang II-induced hypertrophic reaction by directly targeting PTEN mRNA. During cardiomyocyte hypertrophy, attenuation of miR-22 in rat cardiomyocytes efficiently protected them from hypertrophic effects through de-repressing PTEN [150]. PTEN dephosphorylates the phospholipids, which are necessary for membrane targeting and activation of Akt [151]. Interestingly, moderately activated Akt showed cardioprotection, whereas its prolonged chronic activation was detrimental for heart function [152]. Similarly, cardiac mTOR overexpression inhibited necrosis, reduced expression of proinflammatory cytokines, including IL-6 and TNF- $\alpha$ and protected hearts against ischemia-reperfusion injury [153].

In $\mathrm{BOO}$, the role of $\mathrm{PI} 3 \mathrm{~K}$ signaling has not been investigated in great detail however, there is evidence of its importance: activation of this pathway has been reported during bladder hypertrophy in acute and chronic cystitis [154]. In SMC culture models of BOO, hydrostatic pressure stimulated 
cell proliferation via the PI3K/SGK1 signaling pathway [155], emphasizing its importance in mechanotransduction. The growth factor PDGF promotes the division of fibroblasts and members of the PDGF family are involved in myocardial fibrosis [156]. PDGF receptor tyrosine kinase transactivates PI3K-Akt pathway, causing fibrosis. PDGF is released from bladder fibroblasts in response to hydrostatic pressure [157]. In vitro studies in cultured bladder SMCs showed that in response to stretch or mechanical overload PDGF-BB is released and activates PI3K-Akt signaling [158], potentially linking stretch-activated signaling and cell proliferation.

\subsection{ECM and contractile protein remodeling}

Remodeling of ECM takes place in pressure-overloaded hearts and obstructed bladders following activation of the TGF- $\beta$ pathway and leads to increased deposition of collagen and activated synthesis of fibronectin and tropoelastin. In the heart, ECM deposition contributes to organ stiffness and causes a progressive loss of contractility, further exacerbated by the shift in the expression of contractile proteins, including the myosin heavy chain or the alpha-subunit of $\mathrm{Na}+\mathrm{K}(+)$-ATPase towards the fetal type [159]. Similarly, obstruction-induced hypertrophy of the bladder leads to the development of a de-differentiated smooth muscle phenotype, as evidenced in SMCs by a reversal to fetal (non-muscle) gene expression patterns [160]. In addition to their function in regulation of ECM components, several muscle-enriched miRNAs directly affect the expression levels of contractile proteins. MiR-208a is one of the most important heart-enriched miRNAs playing a crucial role in heart health and disease [161]. It is a member of a miRNA family that also includes miR-208b and is encoded by an intronic region of the Myh6 gene. Within the heart, miR-208a and miR-208b are involved in the regulation of the myosin heavy chain isoform switch during development and in pathophysiological conditions. Transgenic overexpression of miR-208a was sufficient to induce hypertrophic cardiac growth in mice, which resulted in pronounced repression of the miR-208 regulatory targets thyroid hormone-associated protein 1 and myostatin, two negative regulators of muscle growth and hypertrophy [162]. MiR-208a was required for proper cardiac conduction and expression of the cardiac transcription factors homeodomain-only protein and GATA4 and the gap junction protein connexin 40 [162]. Down-regulation of this miRNA together with a TNF- $\alpha$ increase activates the complex mediator of transcription 13/nuclear receptor corepressor 1 axis, which in turn promotes MEF2 inhibition. This closes a self-limiting feedback loop, driving the transition from compensation toward decompensation in pulmonary hypertension-induced right ventricular failure [163].

MiR-378, which is expressed in cardiac myocytes [164], is also known to control cardiac hypertrophy by repression of the mitogen-activated protein kinase (MAPK) pathway. Four components of the MAPK pathway, MAPK1, insulin-like growth factor receptor 1 (IGF1R), growth factor receptor bound protein 2 (GRB2) and kinase repressor of ras (KSR1) are among miR-378 targets [165]. Studies in mouse models and humans with heart failure showed that the expression level of miR-378 was significantly decreased compared to non-failing hearts. Thus, a decrease of miR-378 expression is related with the development of cardiac hypertrophy [164]. The roles of 
several TGF- $\beta$-regulated miRNAs, including miR-29, miR-143/145, miR-133a and miR-199a-5p in regulation of ECM and contractile protein expression have been described above.

In the bladder, mechanical strain and traction forces from SMCs are transmitted to the surrounding ECM by coupling molecules including the adhesion molecules integrins, leading to reorganization of ECM during wound repair and pathological fibrosis. In pBOO animal models, a down-regulation of decorin and up-regulation of biglycan, which are markers for fibrotic changes, have been reported [166]. Knock-down of integrin- $\beta 1$ in the urothelium of transgenic mice resulted in bladder overfilling, overactivity and incontinence due to abnormal mechano-transduction [167]. Integrin- $\alpha 1 \beta 1$ is the main collagen receptor involved in reorganization of ECM. Its interaction with collagen is mediated by decorin, which helps ECM fibril packaging and compression [168]. Integrin- $\alpha 1 \beta 1$ plays a role in angiotensin-mediated SM hypertrophy, which is one of the important mechanisms in BOO [169]. Using a mouse model with an induced deletion of Dicer, two groups examined the role of miRNAs in the regulation of bladder contractility. An induced SM-specific Dicer knock-out resulted in significantly reduced levels of miRNAs, including miR-145, miR-143, miR-22, miR-125b-5p and miR-27a, disturbed the micturition pattern in vivo and reduced depolarization-induced pressure development in an isolated detrusor due to decreased levels of L-type $\mathrm{Ca}^{2+}$ channels [170]. In a similar study, the loss of Dicer exacerbated cyclophosphamide-induced bladder overactivity in mice [45].

\section{Therapeutic options for targeting miRNA dysregulation in disease}

The pressure overload- and obstruction-induced hypertrophy and fibrosis of the heart and the bladder share many signaling pathways (Figure 2). Important hubs of signaling activated by pathologic stress are targeted by miRNAs, whose altered expression contributes to the progression of the disease. Restoration and inhibition of miRNA function are the two possible approaches to modulate miRNA activity for therapeutic purposes. Many mature miRNA sequences are conserved among species, allowing direct knowledge transfer from animal models to humans which is a big advantage for drug development [171]. On the other hand, due to the fact that miRNAs regulate a large number of transcripts and each gene can also be regulated by several different miRNAs, the potential off-target effects have to be considered, since changing miRNA expression levels might perturb multiple cellular functions [172]. Delivery of miRNAs and organ- or tissue-specific targeting is a challenge and therefore might require an addition of cell surface receptor ligands to increase specificity [173]. Half-life and/or chemical modification of miRNAs might affect their function and cause toxicity.

MiRNAs are readily inhibited by antisense nucleotides, allowing a "loss-of-function" approach. Antisense oligonucleotides with locked nucleic acid (LNA) modification can be delivered systematically via an injection with little or no toxicity and a half-life sufficient to achieve therapeutic efficacy: LNA-anti-miR-17-5p markedly decreased the area of infarction and apoptosis induced by ischemia following reperfusion in mice [174]. The efficacy of a locked nucleic acid (LNA)-modified 
inhibitor of miR-192, designated LNA-anti-miR-192, was tested in the kidney, where LNA-anti-miR192 significantly reduced levels of miR-192 and decreased renal fibrosis [175]. MiRNA sponges contain multiple tandem binding sites for a miRNA seed family of interest. High expression levels of miRNA sponges inhibit the activity of miRNA families, which share a common seed. The main advantage of miRNA sponges is that functional miRNA classes can be better inhibited than when using antimiR antisense oligonucleotides [176]. In order to induce oligonucleotide uptake, viral vectors can be used. They can also deliver transgenes from miRNA sponges [177].

Many miRNAs play a beneficial role in disease, and their function needs to be restored ("gain-offunction") using synthetic miRNA mimics, which contain chemical modifications to improve stability and cellular uptake [178]. MiRNA mimics need to be delivered as RNA duplexes of guide (i.e. identical to the mature miRNA sequence) and passenger (complementary) strands without the latter inhibiting the function of the former. Supplementation of endogenous miRNA using miRNA mimics (premiRs) has been explored in cystic fibrosis using polymeric nanoparticles for delivery of miR-126 mimic into airway epithelial cells. Polymeric nanoparticles can deliver premiRs effectively in order to modulate gene expression but must be tailored specifically for miRNA delivery [179]. This approach might be interesting for the bladder, which is easily accessible for instillations with solutions containing nanoparticle-conjugated miRNA mimics. Alternatively, in order to optimize the oligonucleotide uptake, viral vectors can be employed. In an animal model of liver fibrosis, a single systemic injection of a miR-29a expressing adeno-associated virus (AAV) prevented and even reversed histologic and biochemical evidence of fibrosis. Given the consistent fibrosis-associated downregulation of miR-29 described in the heart and bladder, AAV-miR-29- based therapies may be an effective treatment option [180].

\section{Future directions}

Despite clear differences in the morphology and function, when faced with cellular stress induced by pressure overload, both the heart and the bladder undergo similar adaptive changes, manifested in activation of the same signaling pathways (Figure 2). Recent high-throughput genomic and transcriptomic studies have been used to identify new pathways and molecular signatures of fibrotic response. Integrative mRNA-miRNA expression profiling studies offer an exciting opportunity to gain insight into the regulatory role of miRNAs in bladder and heart pathologies and identify important hubs of signaling activity among their targets [181]. These studies are well underway in the field of cardiology, and are beginning to emerge in the field of bladder dysfunction.

This Review highlighted the converging roles of miRNAs in the regulation of key signaling processes in the heart and the bladder (summarized in Table 1). Further research in BOO-induced LUTD is needed to add to these data. Molecular leads (both mRNAs and miRNAs) identified during studies of pressure overload in the heart could be tested in animal models of pBOO and human patients' screened to uncover further similarities. 
Circulating miRNAs have been detected in the extracellular space and body fluids and are hailed as biomarkers for cardiovascular and hematological diseases, cancer and CNS disorders. Packaged within exosomes and microvesicles, they are present in a stable form in many body fluids, and might act as key molecules in cell-to-cell communication and signaling. Urine is a useful source of circulating RNAs as it is easy to collect non-invasively in large amounts. Urinary circulating miRNAs could be explored in the context of LUTD and used as diagnostic and/or prognostic markers.

Selective pharmacological interference with pathways activated during the progression from hypertrophy to decompensation/acontractility will allow prevention of organ failure in the heart and the bladder. Identification of the key mRNA targets of miRNAs needs to be followed up by functional validation, and the regulatory role of selected miRNAs in particular signaling pathways should be tested using pharmacologic tools and animal models.

Development and evaluation of miRNA inhibitors of fibrosis will provide a novel therapeutic tool. As discussed above there are several issues which need to be addressed, including safe and precise delivery of miRNAs, possible off-target effects, stability and reversibility of miRNA changes. Despite these challenges, the use of miRNAs as therapeutics holds great promise. Profound understanding of biosynthesis and regulation in different disease processes and validation of target mRNAs is required to fully exploit their potential. Development of precise methods to manipulate miRNA levels with good efficacy over extended periods of time is required. By altering the expression levels of miRNAs, which affect the key signalling pathways activated in fibrosis, it would be possible to prevent acontractility, and assist full restoration of organ function following relief of obstruction, which will be beneficial for ailing hearts and bladders alike.

\section{ACKNOWLEDGMENTS}

We thank Dr. Ali Hashemi Gheinani for his support and assistance during the preparation of this manuscript and Dr. Stéphanie Lecaudé for critical suggestions. The financial support of the Swiss National Science Foundation (SNF Grant 320030_156161/1) and the Velux Foundation (Grant 895) is gratefully acknowledged. We apologize to all authors, whose excellent work could not be mentioned here due to publication size limits.

\section{REFERENCES}

1. Tubaro A, Mariani S, De Nunzio C, Miano R. (2010) Bladder weight and detrusor thickness as parameters of progression of benign prostatic hyperplasia. Current opinion in urology, 20, 37-42.

2. Goldsmith EC, Bradshaw AD, Spinale FG. (2013) Cellular mechanisms of tissue fibrosis. 2. Contributory pathways leading to myocardial fibrosis: moving beyond collagen expression. Am J Physiol Cell Physiol, 304, C393-402.

3. Savinova OV, Gerdes AM. (2012) Myocyte changes in heart failure. Heart Fail Clin, 8, 1-6.

4. Grossman W, Paulus WJ. (2013) Myocardial stress and hypertrophy: a complex interface between biophysics and cardiac remodeling. The Journal of clinical investigation, 123, 37013.

5. Sadoshima J, Izumo S. (1997) The cellular and molecular response of cardiac myocytes to mechanical stress. Annu Rev Physiol, 59, 551-71. 
6. Barry SP, Davidson SM, Townsend PA. (2008) Molecular regulation of cardiac hypertrophy. Int J Biochem Cell Biol, 40, 2023-39.

7. Wakatsuki T, Schlessinger J, Elson EL. (2004) The biochemical response of the heart to hypertension and exercise. Trends Biochem Sci, 29, 609-17.

8. Bernardo BC, Weeks KL, Pretorius L, McMullen JR. (2010) Molecular distinction between physiological and pathological cardiac hypertrophy: experimental findings and therapeutic strategies. Pharmacol Ther, 128, 191-227.

9. Ryan JJ, Archer SL. (2014) The right ventricle in pulmonary arterial hypertension: disorders of metabolism, angiogenesis and adrenergic signaling in right ventricular failure. Circ Res, 115, 176-88.

10. Barnes J, Dell'Italia LJ. (2014) The multiple mechanistic faces of a pure volume overload: implications for therapy. Am J Med Sci, 348, 337-46.

11. Edwards NC, Moody WE, Yuan M, Weale P, Neal D, Townend JN, Steeds RP. (2014) Quantification of left ventricular interstitial fibrosis in asymptomatic chronic primary degenerative mitral regurgitation. Circ Cardiovasc Imaging, 7, 946-53.

12. Reddy S, Zhao M, Hu DQ, Fajardo G, Katznelson E, Punn R, Spin JM, Chan FP, Bernstein D. (2013) Physiologic and molecular characterization of a murine model of right ventricular volume overload. Am J Physiol Heart Circ Physiol, 304, H1314-27.

13. Andersson KE, Arner A. (2004) Urinary bladder contraction and relaxation: physiology and pathophysiology. Physiol Rev, 84, 935-86.

14. Fowler CJ, Griffiths D, de Groat WC. (2008) The neural control of micturition. Nat Rev Neurosci, 9, 453-66.

15. Lee JY, Kim HW, Lee SJ, Koh JS, Suh HJ, Chancellor MB. (2004) Comparison of doxazosin with or without tolterodine in men with symptomatic bladder outlet obstruction and an overactive bladder. BJU Int, 94, 817-20.

16. McNicholas T, Kirby R. (2011) Benign prostatic hyperplasia and male lower urinary tract symptoms (LUTS). Clin Evid (Online), 2011.

17. Yande S, Joshi M. (2011) Bladder outlet obstruction in women. J Midlife Health, 2, 11-7.

18. Hakenberg OW, Linne C, Manseck A, Wirth MP. (2000) Bladder wall thickness in normal adults and men with mild lower urinary tract symptoms and benign prostatic enlargement. Neurourol Urodyn, 19, 585-93.

19. Kojima M, Inui E, Ochiai A, Naya Y, Ukimura O, Watanabe H. (1997) Noninvasive quantitative estimation of infravesical obstruction using ultrasonic measurement of bladder weight. J Urol, 157, 476-9.

20. Krebs J, Bartel P, Pannek J. (2013) Residual urine volumes after intermittent catheterization in men with spinal cord injury. Spinal Cord, 51, 776-9.

21. Myers JB, Dall'era JE, Koul S, Kumar B, Khandrika L, Flynn BJ, Koul HK. (2009) Biochemical alterations in partial bladder outlet obstruction in mice: up-regulation of the mitogen activated protein kinase pathway. J Urol, 181, 1926-31.

22. Chacko S, Chang S, Hypolite J, DiSanto M, Wein A. (2004) Alteration of contractile and regulatory proteins following partial bladder outlet obstruction. Scand.J.Urol.Nephrol.Suppl, 26-36.

23. Metcalfe PD, Wang J, Jiao H, Huang Y, Hori K, Moore RB, Tredget EE. (2010) Bladder outlet obstruction: progression from inflammation to fibrosis. BJU Int, 106, 1686-94.

24. Lee RC, Feinbaum RL, Ambros V. (1993) The C. elegans heterochronic gene lin-4 encodes small RNAs with antisense complementarity to lin-14. Cell, 75, 843-54.

25. Bartel DP. (2009) MicroRNAs: target recognition and regulatory functions. Cell, 136, 215-33.

26. Lagos-Quintana M, Rauhut R, Lendeckel W, Tuschl T. (2001) Identification of novel genes coding for small expressed RNAs. Science, 294, 853-8.

27. Orom UA, Nielsen FC, Lund AH. (2008) MicroRNA-10a binds the 5'UTR of ribosomal protein mRNAs and enhances their translation. Mol Cell, 30, 460-71.

28. Henke JI, Goergen D, Zheng J, Song Y, Schuttler CG, Fehr C, Junemann C, Niepmann M. (2008) microRNA-122 stimulates translation of hepatitis C virus RNA. EMBO J, 27, 3300-10.

29. Tay Y, Zhang J, Thomson AM, Lim B, Rigoutsos I. (2008) MicroRNAs to Nanog, Oct4 and Sox2 coding regions modulate embryonic stem cell differentiation. Nature, 455, 1124-8.

30. Huang S, Wu S, Ding J, Lin J, Wei L, Gu J, He X. (2010) MicroRNA-181a modulates gene expression of zinc finger family members by directly targeting their coding regions. Nucleic Acids Res, 38, 7211-8. 
31. Duursma AM, Kedde M, Schrier M, le Sage C, Agami R. (2008) miR-148 targets human DNMT3b protein coding region. RNA, 14, 872-7.

32. Thomson DW, Bracken CP, Goodall GJ. (2011) Experimental strategies for microRNA target identification. Nucleic Acids Res, 39, 6845-53.

33. Mendell JT, Olson EN. (2012) MicroRNAs in stress signaling and human disease. Cell, 148, 1172-87.

34. Carthew RW, Sontheimer EJ. (2009) Origins and Mechanisms of miRNAs and siRNAs. Cell, 136, 642-55.

35. Chekulaeva M, Filipowicz W. (2009) Mechanisms of miRNA-mediated post-transcriptional regulation in animal cells. Current opinion in cell biology, 21, 452-60.

36. Kim VN, Han J, Siomi MC. (2009) Biogenesis of small RNAs in animals. Nature reviews. Molecular cell biology, 10, 126-39.

37. Friedlander MR, Lizano E, Houben AJ, Bezdan D, Banez-Coronel M, Kudla G, MateuHuertas E, Kagerbauer B, Gonzalez J, Chen KC, LeProust EM, Marti E, Estivill X. (2014) Evidence for the biogenesis of more than 1,000 novel human microRNAs. Genome Biol, 15, R57.

38. Leung AK, Sharp PA. (2007) microRNAs: a safeguard against turmoil? Cell, 130, 581-5.

39. Pandit KV, Milosevic J, Kaminski N. (2011) MicroRNAs in idiopathic pulmonary fibrosis. Transl Res, 157, 191-9.

40. Phanish MK, Wahab NA, Hendry BM, Dockrell ME. (2005) TGF-beta1-induced connective tissue growth factor (CCN2) expression in human renal proximal tubule epithelial cells requires Ras/MEK/ERK and Smad signalling. Nephron Exp Nephrol, 100, e156-65.

41. Tao H, Shi KH, Yang JJ, Huang C, Liu LP, Li J. (2013) Epigenetic regulation of cardiac fibrosis. Cell Signal, 25, 1932-8.

42. Sanchez Freire V, Burkhard FC, Kessler TM, Kuhn A, Draeger A, Monastyrskaya K. (2010) MicroRNAs may mediate the down-regulation of neurokinin-1 receptor in chronic bladder pain syndrome. Am J Pathol, 176, 288-303.

43. Monastyrskaya K, Sanchez-Freire V, Hashemi Gheinani A, Klumpp DJ, Babiychuk EB, Draeger A, Burkhard FC. (2013) miR-199a-5p regulates urothelial permeability and may play a role in bladder pain syndrome. Am J Pathol, 182, 431-48.

44. Hashemi Gheinani A, Burkhard FC, Rehrauer H, Aquino Fournier C, Monastyrskaya K. (2015) MicroRNA MiR-199a-5p Regulates Smooth Muscle Cell Proliferation and Morphology by Targeting WNT2 Signaling Pathway. J Biol Chem, 290, 7067-86.

45. Zhang S, Lv JW, Yang P, Yu Q, Pang J, Wang Z, Guo H, Liu S, Hu J, Li J, Leng J, Huang Y, Ye Z, Wang CY. (2012) Loss of dicer exacerbates cyclophosphamide-induced bladder overactivity by enhancing purinergic signaling. Am J Pathol, 181, 937-46.

46. Ekman M, Bhattachariya A, Dahan D, Uvelius B, Albinsson S, Sward K. (2013) Mir-29 repression in bladder outlet obstruction contributes to matrix remodeling and altered stiffness. PloS one, 8, e82308.

47. Oka T, Akazawa H, Naito AT, Komuro I. (2014) Angiogenesis and cardiac hypertrophy: maintenance of cardiac function and causative roles in heart failure. Circ Res, 114, 565-71.

48. Pichler M, Rainer PP, Schauer S, Hoefler G. (2012) Cardiac fibrosis in human transplanted hearts is mainly driven by cells of intracardiac origin. J Am Coll Cardiol, 59, 1008-16.

49. Kong P, Christia P, Frangogiannis NG. (2014) The pathogenesis of cardiac fibrosis. Cell Mol Life Sci, 71, 549-74.

50. Mantovani A, Sica A, Locati M. (2005) Macrophage polarization comes of age. Immunity, 23, 344-6.

51. Shiota N, Rysa J, Kovanen PT, Ruskoaho H, Kokkonen JO, Lindstedt KA. (2003) A role for cardiac mast cells in the pathogenesis of hypertensive heart disease. J Hypertens, 21, 193544.

52. Mirone V, Imbimbo C, Longo N, Fusco F. (2007) The detrusor muscle: an innocent victim of bladder outlet obstruction. Eur.Urol., 51, 57-66.

53. Zderic SA, Chacko S. (2012) Alterations in the contractile phenotype of the bladder: lessons for understanding physiological and pathological remodelling of smooth muscle. Journal of cellular and molecular medicine, 16, 203-17.

54. Sui GP, Wu C, Roosen A, Ikeda Y, Kanai AJ, Fry CH. (2008) Modulation of bladder myofibroblast activity: implications for bladder function. Am.J.Physiol Renal Physiol, 295, F688-F697. 
55. Scheller J, Chalaris A, Schmidt-Arras D, Rose-John S. (2011) The pro- and antiinflammatory properties of the cytokine interleukin-6. Biochim Biophys Acta, 1813, 878-88.

56. Grover S, Srivastava A, Lee R, Tewari AK, Te AE. (2011) Role of inflammation in bladder function and interstitial cystitis. Ther Adv Urol, 3, 19-33.

57. Kanno Y, Mitsui T, Kitta T, Moriya K, Tsukiyama T, Hatakeyama S, Nonomura K. (2015) The inflammatory cytokine IL-1beta is involved in bladder remodeling after bladder outlet obstruction in mice. Neurourol Urodyn.

58. McMullen JR, Shioi T, Huang WY, Zhang L, Tarnavski O, Bisping E, Schinke M, Kong S, Sherwood MC, Brown J, Riggi L, Kang PM, Izumo S. (2004) The insulin-like growth factor 1 receptor induces physiological heart growth via the phosphoinositide 3-kinase(p110alpha) pathway. J Biol Chem, 279, 4782-93.

59. Fischer P, Hilfiker-Kleiner D. (2008) Role of gp130-mediated signalling pathways in the heart and its impact on potential therapeutic aspects. Br J Pharmacol, 153 Suppl 1, S414-27.

60. Kenessey A, Ojamaa K. (2006) Thyroid hormone stimulates protein synthesis in the cardiomyocyte by activating the Akt-mTOR and p70S6K pathways. J Biol Chem, 281, 20666-72.

61. Sakamoto M, Minamino T, Toko H, Kayama Y, Zou Y, Sano M, Takaki E, Aoyagi T, Tojo K, Tajima N, Nakai A, Aburatani H, Komuro I. (2006) Upregulation of heat shock transcription factor 1 plays a critical role in adaptive cardiac hypertrophy. Circ Res, 99, 1411-8.

62. Lijnen P, Papparella I, Petrov V, Semplicini A, Fagard R. (2006) Angiotensin II-stimulated collagen production in cardiac fibroblasts is mediated by reactive oxygen species. $J$ Hypertens, 24, 757-66.

63. Brunner F, Bras-Silva C, Cerdeira AS, Leite-Moreira AF. (2006) Cardiovascular endothelins: essential regulators of cardiovascular homeostasis. Pharmacol Ther, 111, 508-31.

64. Du XJ. (2008) Distinct role of adrenoceptor subtypes in cardiac adaptation to chronic pressure overload. Clin Exp Pharmacol Physiol, 35, 355-60.

65. Olson EN, Williams RS. (2000) Calcineurin signaling and muscle remodeling. Cell, 101, 68992.

66. Crackower MA, Oudit GY, Kozieradzki I, Sarao R, Sun H, Sasaki T, Hirsch E, Suzuki A, Shioi T, Irie-Sasaki J, Sah R, Cheng HY, Rybin VO, Lembo G, Fratta L, Oliveira-dos-Santos AJ, Benovic JL, Kahn CR, Izumo S, Steinberg SF, Wymann MP, Backx PH, Penninger JM. (2002) Regulation of myocardial contractility and cell size by distinct PI3K-PTEN signaling pathways. Cell, 110, 737-49.

67. Molkentin JD, Lu JR, Antos CL, Markham B, Richardson J, Robbins J, Grant SR, Olson EN. (1998) A calcineurin-dependent transcriptional pathway for cardiac hypertrophy. Cell, 93, 215-28.

68. Hogan PG, Chen L, Nardone J, Rao A. (2003) Transcriptional regulation by calcium, calcineurin, and NFAT. Genes Dev, 17, 2205-32.

69. Haq S, Choukroun G, Lim H, Tymitz KM, del Monte F, Gwathmey J, Grazette L, Michael A, Hajjar R, Force T, Molkentin JD. (2001) Differential activation of signal transduction pathways in human hearts with hypertrophy versus advanced heart failure. Circulation, 103, 670-7.

70. Saito T, Fukuzawa J, Osaki J, Sakuragi H, Yao N, Haneda T, Fujino T, Wakamiya N, Kikuchi K, Hasebe N. (2003) Roles of calcineurin and calcium/calmodulin-dependent protein kinase II in pressure overload-induced cardiac hypertrophy. Journal of molecular and cellular cardiology, 35, 1153-60.

71. Chen JF, Mandel EM, Thomson JM, Wu Q, Callis TE, Hammond SM, Conlon FL, Wang DZ. (2006) The role of microRNA-1 and microRNA-133 in skeletal muscle proliferation and differentiation. Nat Genet, 38, 228-33.

72. Care A, Catalucci D, Felicetti F, Bonci D, Addario A, Gallo P, Bang ML, Segnalini P, Gu Y, Dalton ND, Elia L, Latronico MV, Hoydal M, Autore C, Russo MA, Dorn GW, 2nd, Ellingsen O, Ruiz-Lozano P, Peterson KL, Croce CM, Peschle C, Condorelli G. (2007) MicroRNA-133 controls cardiac hypertrophy. Nat Med, 13, 613-8.

73. Zhao Y, Samal E, Srivastava D. (2005) Serum response factor regulates a muscle-specific microRNA that targets Hand2 during cardiogenesis. Nature, 436, 214-20.

74. Rao PK, Toyama Y, Chiang HR, Gupta S, Bauer M, Medvid R, Reinhardt F, Liao R, Krieger M, Jaenisch R, Lodish HF, Blelloch R. (2009) Loss of cardiac microRNA-mediated regulation leads to dilated cardiomyopathy and heart failure. Circ Res, 105, 585-94. 
75. Ikeda S, He A, Kong SW, Lu J, Bejar R, Bodyak N, Lee KH, Ma Q, Kang PM, Golub TR, Pu WT. (2009) MicroRNA-1 negatively regulates expression of the hypertrophy-associated calmodulin and Mef2a genes. Mol.Cell Biol., 29, 2193-2204.

76. Li Q, Lin X, Yang X, Chang J. (2010) NFATc4 is negatively regulated in miR-133a-mediated cardiomyocyte hypertrophic repression. Am J Physiol Heart Circ Physiol, 298, H1340-7.

77. Dong DL, Chen C, Huo R, Wang N, Li Z, Tu YJ, Hu JT, Chu X, Huang W, Yang BF. (2010) Reciprocal repression between microRNA-133 and calcineurin regulates cardiac hypertrophy: a novel mechanism for progressive cardiac hypertrophy. Hypertension, 55, 946-52.

78. Ucar A, Gupta SK, Fiedler J, Erikci E, Kardasinski M, Batkai S, Dangwal S, Kumarswamy R, Bang C, Holzmann A, Remke J, Caprio M, Jentzsch C, Engelhardt S, Geisendorf S, Glas C, Hofmann TG, Nessling M, Richter K, Schiffer M, Carrier L, Napp LC, Bauersachs J, Chowdhury K, Thum T. (2012) The miRNA-212/132 family regulates both cardiac hypertrophy and cardiomyocyte autophagy. Nat Commun, 3, 1078.

79. Kumarswamy R, Lyon AR, Volkmann I, Mills AM, Bretthauer J, Pahuja A, Geers-Knorr C, Kraft T, Hajjar RJ, Macleod KT, Harding SE, Thum T. (2012) SERCA2a gene therapy restores microRNA-1 expression in heart failure via an Akt/FoxO3A-dependent pathway. Eur Heart J, 33, 1067-75.

80. Wang JX, Jiao JQ, Li Q, Long B, Wang K, Liu JP, Li YR, Li PF. (2011) miR-499 regulates mitochondrial dynamics by targeting calcineurin and dynamin-related protein-1. Nat Med, 17, 71-8.

81. Huang ZP, Chen J, Seok HY, Zhang Z, Kataoka M, Hu X, Wang DZ. (2013) MicroRNA-22 regulates cardiac hypertrophy and remodeling in response to stress. Circ Res, 112, 1234-43.

82. Lin Z, Murtaza I, Wang K, Jiao J, Gao J, Li PF. (2009) miR-23a functions downstream of NFATc3 to regulate cardiac hypertrophy. Proc Natl Acad Sci U S A, 106, 12103-8.

83. da Costa Martins PA, Salic K, Gladka MM, Armand AS, Leptidis S, el Azzouzi H, Hansen A, Coenen-de Roo CJ, Bierhuizen MF, van der Nagel R, van Kuik J, de Weger R, de Bruin A, Condorelli G, Arbones ML, Eschenhagen T, De Windt LJ. (2010) MicroRNA-199b targets the nuclear kinase Dyrk1a in an auto-amplification loop promoting calcineurin/NFAT signalling. Nat Cell Biol, 12, 1220-7.

84. Chang AY, Sliwoski J, Butler S, Hearn G, Lassmann J, Chacko S, Canning DA, Zderic SA. (2011) Calcineurin mediates bladder wall remodeling secondary to partial outlet obstruction. Am J Physiol Renal Physiol, 301, F813-22.

85. Sadegh MK, Ekman M, Krawczyk K, Svensson D, Goransson O, Dahan D, Nilsson BO, Albinsson S, Uvelius B, Sward K. (2015) Detrusor induction of miR-132/212 following bladder outlet obstruction: association with MeCP2 repression and cell viability. PLoS One, 10, e0116784.

86. Bowen T, Jenkins RH, Fraser DJ. (2013) MicroRNAs, transforming growth factor beta-1, and tissue fibrosis. J Pathol, 229, 274-85.

87. Meng XM, Chung AC, Lan HY. (2013) Role of the TGF-beta/BMP-7/Smad pathways in renal diseases. Clin Sci (Lond), 124, 243-54.

88. Koitabashi N, Danner T, Zaiman AL, Pinto YM, Rowell J, Mankowski J, Zhang D, Nakamura T, Takimoto E, Kass DA. (2011) Pivotal role of cardiomyocyte TGF-beta signaling in the murine pathological response to sustained pressure overload. The Journal of clinical investigation, 121, 2301-12.

89. Adhikari A, Xu M, Chen ZJ. (2007) Ubiquitin-mediated activation of TAK1 and IKK. Oncogene, 26, 3214-26.

90. Schroer AK, Merryman WD. (2015) Mechanobiology of myofibroblast adhesion in fibrotic cardiac disease. J Cell Sci.

91. Leask A. (2010) Potential therapeutic targets for cardiac fibrosis: TGFbeta, angiotensin, endothelin, CCN2, and PDGF, partners in fibroblast activation. Circ Res, 106, 1675-80.

92. Petrov VV, Fagard RH, Lijnen PJ. (2002) Stimulation of collagen production by transforming growth factor-beta1 during differentiation of cardiac fibroblasts to myofibroblasts. Hypertension, 39, 258-63.

93. Baum J, Duffy HS. (2011) Fibroblasts and myofibroblasts: what are we talking about? J Cardiovasc Pharmacol, 57, 376-9.

94. Deaton RA, Su C, Valencia TG, Grant SR. (2005) Transforming growth factor-beta1-induced expression of smooth muscle marker genes involves activation of PKN and p38 MAPK. J Biol Chem, 280, 31172-81. 
95. Song YS, Lee HJ, Doo SH, Lee SJ, Lim I, Chang KT, Kim SU. (2012) Mesenchymal stem cells overexpressing hepatocyte growth factor (HGF) inhibit collagen deposit and improve bladder function in rat model of bladder outlet obstruction. Cell Transplant, 21, 1641-50.

96. Chen MW, Levin RM, Buttyan R. (1995) Peptide growth factors in normal and hypertrophied bladder. World J Urol, 13, 344-8.

97. Gheinani AH, Burkhard FC, Monastyrskaya K. (2013) Deciphering microRNA code in pain and inflammation: lessons from bladder pain syndrome. Cell Mol Life Sci.

98. Jenkins RH, Martin J, Phillips AO, Bowen T, Fraser DJ. (2012) Pleiotropy of microRNA-192 in the kidney. Biochem Soc Trans, 40, 762-7.

99. Chung AC, Huang XR, Meng X, Lan HY. (2010) miR-192 mediates TGF-beta/Smad3-driven renal fibrosis. J Am Soc Nephrol, 21, 1317-25.

100. Wang B, Herman-Edelstein M, Koh P, Burns W, Jandeleit-Dahm K, Watson A, Saleem M, Goodall GJ, Twigg SM, Cooper ME, Kantharidis P. (2010) E-cadherin expression is regulated by miR-192/215 by a mechanism that is independent of the profibrotic effects of transforming growth factor-beta. Diabetes, 59, 1794-802.

101. Hong JP, Li XM, Li MX, Zheng FL. (2013) VEGF suppresses epithelial-mesenchymal transition by inhibiting the expression of Smad3 and miR192, a Smad3-dependent microRNA. Int J Mol Med, 31, 1436-42.

102. Thum T, Gross C, Fiedler J, Fischer T, Kissler S, Bussen M, Galuppo P, Just S, Rottbauer W, Frantz S, Castoldi M, Soutschek J, Koteliansky V, Rosenwald A, Basson MA, Licht JD, Pena JT, Rouhanifard SH, Muckenthaler MU, Tuschl T, Martin GR, Bauersachs J, Engelhardt S. (2008) MicroRNA-21 contributes to myocardial disease by stimulating MAP kinase signalling in fibroblasts. Nature, 456, 980-4.

103. Taniyama Y, Morishita R, Nakagami H, Moriguchi A, Sakonjo H, Shokei K, Matsumoto K, Nakamura T, Higaki J, Ogihara T. (2000) Potential contribution of a novel antifibrotic factor, hepatocyte growth factor, to prevention of myocardial fibrosis by angiotensin II blockade in cardiomyopathic hamsters. Circulation, 102, 246-52.

104. Mungunsukh O, Day RM. (2013) TGF-beta1 Selectively Inhibits Hepatocyte Growth Factor Expression via an miR-199-dependent Posttranscriptional Mechanism. Mol Biol Cell.

105. Kwiecinski M, Noetel A, Elfimova N, Trebicka J, Schievenbusch S, Strack I, Molnar L, von Brandenstein M, Tox U, Nischt R, Coutelle O, Dienes HP, Odenthal M. (2011) Hepatocyte growth factor (HGF) inhibits collagen I and IV synthesis in hepatic stellate cells by miRNA-29 induction. PloS one, 6, e24568.

106. Xin M, Small EM, Sutherland LB, Qi X, McAnally J, Plato CF, Richardson JA, Bassel-Duby R, Olson EN. (2009) MicroRNAs miR-143 and miR-145 modulate cytoskeletal dynamics and responsiveness of smooth muscle cells to injury. Genes \& development, 23, 2166-78.

107. Long X, Miano JM. (2011) Transforming growth factor-beta1 (TGF-beta1) utilizes distinct pathways for the transcriptional activation of microRNA 143/145 in human coronary artery smooth muscle cells. J Biol Chem, 286, 30119-29.

108. Lino Cardenas CL, Henaoui IS, Courcot E, Roderburg C, Cauffiez C, Aubert S, Copin MC, Wallaert B, Glowacki F, Dewaeles E, Milosevic J, Maurizio J, Tedrow J, Marcet B, LoGuidice JM, Kaminski N, Barbry P, Luedde T, Perrais M, Mari B, Pottier N. (2013) miR-199a$5 p$ Is upregulated during fibrogenic response to tissue injury and mediates TGFbeta-induced lung fibroblast activation by targeting caveolin-1. PLoS genetics, 9, e1003291.

109. Rane S, He M, Sayed D, Vashistha H, Malhotra A, Sadoshima J, Vatner DE, Vatner SF, Abdellatif M. (2009) Downregulation of miR-199a derepresses hypoxia-inducible factor1alpha and Sirtuin 1 and recapitulates hypoxia preconditioning in cardiac myocytes. Circ Res, 104, 879-86.

110. Song XW, Li Q, Lin L, Wang XC, Li DF, Wang GK, Ren AJ, Wang YR, Qin YW, Yuan WJ, Jing Q. (2010) MicroRNAs are dynamically regulated in hypertrophic hearts, and miR-199a is essential for the maintenance of cell size in cardiomyocytes. J Cell Physiol, 225, 437-43.

111. Alexander MS, Kawahara G, Motohashi N, Casar JC, Eisenberg I, Myers JA, Gasperini MJ, Estrella EA, Kho AT, Mitsuhashi S, Shapiro F, Kang PB, Kunkel LM. (2013) MicroRNA-199a is induced in dystrophic muscle and affects WNT signaling, cell proliferation, and myogenic differentiation. Cell death and differentiation, 20, 1194-208.

112. Kontaraki JE, Parthenakis FI, Patrianakos AP, Karalis IK, Vardas PE. (2007) Altered expression of early cardiac marker genes in circulating cells of patients with hypertrophic cardiomyopathy. Cardiovasc Pathol, 16, 329-35. 
113. Torrado M, Iglesias R, Centeno A, Lopez E, Mikhailov AT. (2011) Targeted gene-silencing reveals the functional significance of myocardin signaling in the failing heart. PloS one, 6 , e26392.

114. Chiu CZ, Wang BW, Shyu KG. (2012) Use of atorvastatin to inhibit hypoxia-induced myocardin expression. Eur J Clin Invest, 42, 564-71.

115. el Azzouzi H, Leptidis S, Dirkx E, Hoeks J, van Bree B, Brand K, McClellan EA, Poels E, Sluimer JC, van den Hoogenhof MM, Armand AS, Yin X, Langley S, Bourajjaj M, Olieslagers S, Krishnan J, Vooijs M, Kurihara H, Stubbs A, Pinto YM, Krek W, Mayr M, da Costa Martins PA, Schrauwen P, De Windt LJ. (2013) The hypoxia-inducible microRNA cluster miR-199a approximately 214 targets myocardial PPARdelta and impairs mitochondrial fatty acid oxidation. Cell Metab, 18, 341-54.

116. Yoshida T, Yamashita M, Horimai C, Hayashi M. (2014) Kruppel-like factor 4 protein regulates isoproterenol-induced cardiac hypertrophy by modulating myocardin expression and activity. J Biol Chem, 289, 26107-18.

117. van Rooij E, Olson EN. (2009) Searching for miR-acles in cardiac fibrosis. Circ Res, 104, 138-40.

118. van Rooij E, Sutherland LB, Thatcher JE, DiMaio JM, Naseem RH, Marshall WS, Hill JA, Olson EN. (2008) Dysregulation of microRNAs after myocardial infarction reveals a role of miR-29 in cardiac fibrosis. Proc Natl Acad Sci U S A, 105, 13027-32.

119. Liu N, Bezprozvannaya S, Williams AH, Qi X, Richardson JA, Bassel-Duby R, Olson EN. (2008) microRNA-133a regulates cardiomyocyte proliferation and suppresses smooth muscle gene expression in the heart. Genes \& development, 22, 3242-54.

120. Duan LJ, Qi J, Kong XJ, Huang T, Qian XQ, Xu D, Liang JH, Kang J. (2015) MiR-133 modulates TGF-beta1-induced bladder smooth muscle cell hypertrophic and fibrotic response: implication for a role of microRNA in bladder wall remodeling caused by bladder outlet obstruction. Cell Signal, 27, 215-27.

121. Imamura M, Sugino Y, Long X, Slivano OJ, Nishikawa N, Yoshimura N, Miano JM. (2013) Myocardin and microRNA-1 modulate bladder activity through connexin 43 expression during post-natal development. J Cell Physiol, 228, 1819-26.

122. Simoes e Silva AC, Silveira KD, Ferreira AJ, Teixeira MM. (2013) ACE2, angiotensin-(1-7) and Mas receptor axis in inflammation and fibrosis. Br J Pharmacol, 169, 477-92.

123. Kong P, Christia P, Frangogiannis NG. (2013) The pathogenesis of cardiac fibrosis. Cell Mol Life Sci.

124. Lijnen P, Petrov V. (1999) Renin-angiotensin system, hypertrophy and gene expression in cardiac myocytes. Journal of molecular and cellular cardiology, 31, 949-70.

125. Devereux RB. (2000) Therapeutic options in minimizing left ventricular hypertrophy. Am Heart J, 139, S9-14.

126. Tobu S, Noguchi M, Hatada T, Mori K, Matsuo M, Sakai H. (2012) Changes in angiotensin II type 1 receptor expression in the rat bladder by bladder outlet obstruction. Urol Int, 89, 241 5.

127. Comiter C, Phull HS. (2012) Angiotensin II type 1 (AT-1) receptor inhibition partially prevents the urodynamic and detrusor changes associated with bladder outlet obstruction: a mouse model. BJU Int, 109, 1841-6.

128. Ren M, Hao S, Yang C, Zhu P, Chen L, Lin D, Li N, Yan L. (2013) Angiotensin II regulates collagen metabolism through modulating tissue inhibitor of metalloproteinase-1 in diabetic skin tissues. Diab Vasc Dis Res.

129. Jeppesen PL, Christensen GL, Schneider M, Nossent AY, Jensen HB, Andersen DC, Eskildsen T, Gammeltoft S, Hansen JL, Sheikh SP. (2011) Angiotensin II type 1 receptor signalling regulates microRNA differentially in cardiac fibroblasts and myocytes. $\mathrm{Br} J$ Pharmacol, 164, 394-404.

130. Eskildsen TV, Jeppesen PL, Schneider M, Nossent AY, Sandberg MB, Hansen PB, Jensen $\mathrm{CH}$, Hansen ML, Marcussen N, Rasmussen LM, Bie P, Andersen DC, Sheikh SP. (2013) Angiotensin II Regulates microRNA-132/-212 in Hypertensive Rats and Humans. Int J Mol Sci, 14, 11190-207.

131. Sano M, Fukuda K, Kodama H, Takahashi T, Kato T, Hakuno D, Sato T, Manabe T, Tahara S, Ogawa S. (2000) Autocrine/Paracrine secretion of IL-6 family cytokines causes angiotensin II-induced delayed STAT3 activation. Biochem Biophys Res Commun, 269, 798802. 
132. Fredj S, Bescond J, Louault C, Delwail A, Lecron JC, Potreau D. (2005) Role of interleukin-6 in cardiomyocyte/cardiac fibroblast interactions during myocyte hypertrophy and fibroblast proliferation. J Cell Physiol, 204, 428-36.

133. Martin MM, Lee EJ, Buckenberger JA, Schmittgen TD, Elton TS. (2006) MicroRNA-155 regulates human angiotensin II type 1 receptor expression in fibroblasts. J Biol Chem, 281, 18277-84.

134. Seok HY, Chen J, Kataoka M, Huang ZP, Ding J, Yan J, Hu X, Wang DZ. (2014) Loss of MicroRNA-155 protects the heart from pathological cardiac hypertrophy. Circ Res, 114, 1585-95.

135. Semenza GL. (2014) Hypoxia-inducible factor 1 and cardiovascular disease. Annu Rev Physiol, 76, 39-56.

136. Ghafar MA, Anastasiadis AG, Olsson LE, Chichester P, Kaplan SA, Buttyan R, Levin RM. (2002) Hypoxia and an angiogenic response in the partially obstructed rat bladder. Lab Invest, 82, 903-9.

137. Kehat I, Molkentin JD. (2010) Molecular pathways underlying cardiac remodeling during pathophysiological stimulation. Circulation, 122, 2727-35.

138. Chemaly ER, Kang S, Zhang S, McCollum L, Chen J, Benard L, Purushothaman KR, Hajjar RJ, Lebeche D. (2013) Differential patterns of replacement and reactive fibrosis in pressure and volume overload are related to the propensity for ischaemia and involve resistin. $J$ Physiol, 591, 5337-55.

139. Song YS, Lee HJ, Doo SW, An J, Kim SU. (2013) Enhanced angiogenesis and relaxation of bladder as early response to bladder outlet obstruction. International journal of urology : official journal of the Japanese Urological Association, 20, 116-22.

140. Burgu B, Medina Ortiz WE, Pitera JE, Woolf AS, Wilcox DT. (2007) Vascular endothelial growth factor mediates hypoxic stimulated embryonic bladder growth in organ culture. J.Urol., 177, 1552-1557.

141. Ekman M, Uvelius B, Albinsson S, Sward K. (2014) HIF-mediated metabolic switching in bladder outlet obstruction mitigates the relaxing effect of mitochondrial inhibition. Lab Invest, 94, 557-68.

142. Davis BN, Hilyard AC, Nguyen PH, Lagna G, Hata A. (2009) Induction of microRNA-221 by platelet-derived growth factor signaling is critical for modulation of vascular smooth muscle phenotype. J Biol Chem, 284, 3728-38.

143. Crosby ME, Devlin CM, Glazer PM, Calin GA, Ivan M. (2009) Emerging roles of microRNAs in the molecular responses to hypoxia. Curr.Pharm.Des, 15, 3861-3866.

144. Kulshreshtha R, Ferracin M, Wojcik SE, Garzon R, Alder H, Agosto-Perez FJ, Davuluri R, Liu CG, Croce CM, Negrini M, Calin GA, Ivan M. (2007) A microRNA signature of hypoxia. Mol Cell Biol, 27, 1859-67.

145. Gee HE, Camps C, Buffa FM, Patiar S, Winter SC, Betts G, Homer J, Corbridge R, Cox G, West CM, Ragoussis J, Harris AL. (2010) hsa-mir-210 is a marker of tumor hypoxia and a prognostic factor in head and neck cancer. Cancer, 116, 2148-58.

146. Gou D, Ramchandran R, Peng X, Yao L, Kang K, Sarkar J, Wang Z, Zhou G, Raj JU. (2012) miR-210 has an antiapoptotic effect in pulmonary artery smooth muscle cells during hypoxia. Am J Physiol Lung Cell Mol Physiol, 303, L682-91.

147. Aoyagi T, Matsui T. (2011) Phosphoinositide-3 kinase signaling in cardiac hypertrophy and heart failure. Curr Pharm Des, 17, 1818-24.

148. Stitt TN, Drujan D, Clarke BA, Panaro F, Timofeyva Y, Kline WO, Gonzalez M, Yancopoulos GD, Glass DJ. (2004) The IGF-1/PI3K/Akt pathway prevents expression of muscle atrophyinduced ubiquitin ligases by inhibiting FOXO transcription factors. Mol Cell, 14, 395-403.

149. Roy S, Khanna S, Hussain SR, Biswas S, Azad A, Rink C, Gnyawali S, Shilo S, Nuovo GJ, Sen CK. (2009) MicroRNA expression in response to murine myocardial infarction: miR-21 regulates fibroblast metalloprotease-2 via phosphatase and tensin homologue. Cardiovasc Res, 82, 21-9.

150. Xu XD, Song XW, Li Q, Wang GK, Jing Q, Qin YW. (2012) Attenuation of microRNA-22 derepressed PTEN to effectively protect rat cardiomyocytes from hypertrophy. J Cell Physiol, 227, 1391-8.

151. Oudit GY, Penninger JM. (2009) Cardiac regulation by phosphoinositide 3-kinases and PTEN. Cardiovasc Res, 82, 250-60. 
152. Matsui T, Li L, Wu JC, Cook SA, Nagoshi T, Picard MH, Liao R, Rosenzweig A. (2002) Phenotypic spectrum caused by transgenic overexpression of activated Akt in the heart. $J$ Biol Chem, 277, 22896-901.

153. Aoyagi T, Kusakari Y, Xiao CY, Inouye BT, Takahashi M, Scherrer-Crosbie M, Rosenzweig A, Hara K, Matsui T. (2012) Cardiac mTOR protects the heart against ischemia-reperfusion injury. Am J Physiol Heart Circ Physiol, 303, H75-85.

154. Qiao Z, Xia C, Shen S, Corwin FD, Liu M, Guan R, Grider JR, Qiao LY. (2014) Suppression of the PI3K pathway in vivo reduces cystitis-induced bladder hypertrophy and restores bladder capacity examined by magnetic resonance imaging. PloS one, 9, e114536.

155. Chen L, Wei TQ, Wang Y, Zhang J, Li H, Wang KJ. (2012) Simulated bladder pressure stimulates human bladder smooth muscle cell proliferation via the PI3K/SGK1 signaling pathway. J Urol, 188, 661-7.

156. Andrae J, Gallini R, Betsholtz C. (2008) Role of platelet-derived growth factors in physiology and medicine. Genes Dev, 22, 1276-312.

157. Akbal C, Lee SD, Jung C, Rink R, Kaefer M. (2006) Upregulation of both PDGF-BB and PDGF-BB receptor in human bladder fibroblasts in response to physiologic hydrostatic pressure. J Pediatr Urol, 2, 402-8.

158. Adam RM, Roth JA, Cheng HL, Rice DC, Khoury J, Bauer SB, Peters CA, Freeman MR. (2003) Signaling through PI3K/Akt mediates stretch and PDGF-BB-dependent DNA synthesis in bladder smooth muscle cells. J Urol, 169, 2388-93.

159. Moalic JM, Charlemagne D, Mansier P, Chevalier B, Swynghedauw B. (1993) Cardiac hypertrophy and failure--a disease of adaptation. Modifications in membrane proteins provide a molecular basis for arrhythmogenicity. Circulation, 87, IV21-6.

160. Lin VK, McConnell JD. (1995) Molecular aspects of bladder outlet obstruction. Adv Exp Med Biol, 385, 65-74; discussion 75-9.

161. Montgomery RL, Hullinger TG, Semus HM, Dickinson BA, Seto AG, Lynch JM, Stack C, Latimer PA, Olson EN, van Rooij E. (2011) Therapeutic inhibition of miR-208a improves cardiac function and survival during heart failure. Circulation, 124, 1537-47.

162. Callis TE, Pandya K, Seok HY, Tang RH, Tatsuguchi M, Huang ZP, Chen JF, Deng Z, Gunn B, Shumate J, Willis MS, Selzman CH, Wang DZ. (2009) MicroRNA-208a is a regulator of cardiac hypertrophy and conduction in mice. The Journal of clinical investigation, 119, 277286.

163. Paulin R, Sutendra G, Gurtu V, Dromparis P, Haromy A, Provencher S, Bonnet S, Michelakis ED. (2015) A miR-208-Mef2 axis drives the decompensation of right ventricular function in pulmonary hypertension. Circ Res, 116, 56-69.

164. Nagalingam RS, Sundaresan NR, Gupta MP, Geenen DL, Solaro RJ, Gupta M. (2013) A cardiac-enriched microRNA, miR-378, blocks cardiac hypertrophy by targeting Ras signaling. J Biol Chem, 288, 11216-32.

165. Ganesan J, Ramanujam D, Sassi Y, Ahles A, Jentzsch C, Werfel S, Leierseder S, Loyer X, Giacca M, Zentilin L, Thum T, Laggerbauer B, Engelhardt S. (2013) MiR-378 controls cardiac hypertrophy by combined repression of mitogen-activated protein kinase pathway factors. Circulation, 127, 2097-106.

166. Maciejewski CC, Honardoust D, Tredget EE, Metcalfe PD. (2012) Differential expression of class I small leucine-rich proteoglycans in an animal model of partial bladder outlet obstruction. J Urol, 188, 1543-8.

167. Kanasaki K, Yu W, von Bodungen M, Larigakis JD, Kanasaki M, Ayala de la Pena F, Kalluri R, Hill WG. (2013) Loss of beta1-integrin from urothelium results in overactive bladder and incontinence in mice: a mechanosensory rather than structural phenotype. FASEB J, 27, 1950-61.

168. Jarvelainen H, Vernon RB, Gooden MD, Francki A, Lara S, Johnson PY, Kinsella MG, Sage $\mathrm{EH}$, Wight TN. (2004) Overexpression of decorin by rat arterial smooth muscle cells enhances contraction of type I collagen in vitro. Arterioscler Thromb Vasc Biol, 24, 67-72.

169. Aikawa K, Sakai T, Ishibashi K, Shiomi H, Sagawa K, Kumagai S, Kataoka M, Akaihata H, Yamaguchi O. (2012) Involvement of angiotensin II type 1 receptor on pathological remodeling and dysfunction in obstructed bladder. Int J Urol, 19, 457-64.

170. Sadegh MK, Ekman M, Rippe C, Uvelius B, Sward K, Albinsson S. (2012) Deletion of Dicer in smooth muscle affects voiding pattern and reduces detrusor contractility and neuroeffector transmission. PloS one, 7, e35882. 
171. van Rooij E. (2012) Introduction to the series on microRNAs in the cardiovascular system. Circ Res, 110, 481-2.

172. Singh S, Narang AS, Mahato RI. (2011) Subcellular fate and off-target effects of siRNA, shRNA, and miRNA. Pharmaceutical research, 28, 2996-3015.

173. van Rooij E, Marshall WS, Olson EN. (2008) Toward microRNA-based therapeutics for heart disease: the sense in antisense. Circ Res, 103, 919-28.

174. Du W, Pan Z, Chen X, Wang L, Zhang Y, Li S, Liang H, Xu C, Wu Y, Shan H, Lu Y. (2014) By targeting Stat3 microRNA-17-5p promotes cardiomyocyte apoptosis in response to ischemia followed by reperfusion. Cell Physiol Biochem, 34, 955-65.

175. Putta S, Lanting L, Sun G, Lawson G, Kato M, Natarajan R. (2012) Inhibiting microRNA-192 ameliorates renal fibrosis in diabetic nephropathy. J Am Soc Nephrol, 23, 458-69.

176. Wang Z, Luo X, Lu Y, Yang B. (2008) miRNAs at the heart of the matter. J Mol Med (Berl), 86, 771-83.

177. Ebert MS, Sharp PA. (2010) MicroRNA sponges: progress and possibilities. RNA, 16, 204350.

178. Thorsen SB, Obad S, Jensen NF, Stenvang J, Kauppinen S. (2012) The therapeutic potential of microRNAs in cancer. Cancer J, 18, 275-84.

179. McKiernan PJ, Cunningham O, Greene CM, Cryan SA. (2013) Targeting miRNA-based medicines to cystic fibrosis airway epithelial cells using nanotechnology. Int $\mathrm{J}$ Nanomedicine, 8, 3907-15.

180. Knabel MK, Ramachandran K, Karhadkar S, Hwang HW, Creamer TJ, Chivukula RR, Sheikh F, Clark KR, Torbenson M, Montgomery RA, Cameron AM, Mendell JT, Warren DS. (2015) Systemic Delivery of scAAV8-Encoded MiR-29a Ameliorates Hepatic Fibrosis in Carbon Tetrachloride-Treated Mice. PloS one, 10, e0124411.

181. Hirt MN, Werner T, Indenbirken D, Alawi M, Demin P, Kunze AC, Stenzig J, Starbatty J, Hansen A, Fiedler J, Thum T, Eschenhagen T. (2015) Deciphering the microRNA signature of pathological cardiac hypertrophy by engineered heart tissue- and sequencing-technology. Journal of molecular and cellular cardiology, 81, 1-9. 


\section{FIGURE LEGENDS}

Figure 1: MicroRNA miR-199a-5p in smooth muscle differentiation and hypertrophy.

Increased expression of miR-199a-5p in smooth muscle cells affects WNT signaling by downregulating WNT2 and influences cytoskeleton remodeling.

1) Inhibition of WNT signaling pathway leads to down-regulation of KLF4, a WNT-dependent repressor of the myocardin synthesis and the transcription of SRF/myocardin-stimulated genes. KLF4 decrease leads to elevation of myocardin levels. Together with SRF myocardin then induces genes encoding SM-specific and contractile proteins, including SM22, SM $\alpha$-actin (ACTA2), SM myosin heavy chain (MYH11), transforming growth factor-beta 1-induced transcript 1 (TGFB1I1).

2) MiR-199a-5p-regulated cytoskeleton remodeling activates actin-dependent MRTF-A, which translocates to the nucleus, associates with SRF and stimulates expression of MYL9 and Id3. Id3 is a part of regulatory network, promoting smooth muscle differentiation. The resulting increase in synthesis of contractile and structural proteins leads to SMC hypertrophy. Based on [44].

\section{Figure 2: Common signaling pathways in the bladder and the heart.}

Bladder and heart follow the same regulatory mechanisms leading to hypertrophy, fibrosis and contractility defects. $\mathrm{Ca}^{2+}{ }^{+}$-dependent phosphatase calcineurin - NFAT, TGF- $\beta$, Renin-angiotensin system (RAS), Hypoxia, Phosphoinositide 3-kinase (PI3K) signaling, and CaMk/MEF2 signaling cause hypertrophy in both organs. TGF- $\beta$, Renin-angiotensin system (RAS), Hypoxia and ECM remodeling result in fibrosis in the bladder and the heart tissue. Contractility defects can arise in both organs from the alterations of CaMk/MEF2 signaling. 
Table 1. Common miRNAs altered in bladder and heart pathologies.

\begin{tabular}{|l|c|c|c|c|}
\hline \multicolumn{1}{|c|}{ MicroRNA } & \multicolumn{2}{|c|}{ Bladder } & \multicolumn{2}{c|}{ Heart } \\
\hline miR-199a-5p & Regulation & \multicolumn{1}{|c|}{ Function } & Regulation & Function \\
& Up & $\begin{array}{l}\text { Increases urothelium } \\
\text { permeability [43] and } \\
\text { SMC differentiation, reduces } \\
\text { proliferation [44] }\end{array}$ & Up & $\begin{array}{l}\text { Promotes } \\
\text { cardiac } \\
\text { hypertrophy } \\
{[110]}\end{array}$ \\
\hline miR-212/132 & Up & $\begin{array}{l}\text { Increases cell size and } \\
\text { proliferation [85] }\end{array}$ & Up & $\begin{array}{l}\text { Induces cardiac } \\
\text { hypertrophy and } \\
\text { represses } \\
\text { autophagy [78] }\end{array}$ \\
\hline miR-133 & Down & $\begin{array}{l}\text { Induces contractile protein } \\
\text { synthesis, reduces bladder } \\
\text { fibrosis [120] }\end{array}$ & Down & $\begin{array}{l}\text { Reduces cardiac } \\
\text { hypertrophy [76] }\end{array}$ \\
\hline miR-1 & Down & $\begin{array}{l}\text { Reduces connexin-mediated } \\
\text { bladder overactivity [121] }\end{array}$ & Down & $\begin{array}{l}\text { Down-regulates } \\
\text { MEF2a and } \\
\text { GATA4 [75] }\end{array}$ \\
\hline miR-29c & Down & $\begin{array}{l}\text { Reduces collagen } \\
\text { expression and bladder } \\
\text { stiffness [46] }\end{array}$ & Down & $\begin{array}{l}\text { Reduces fibrosis } \\
\text { [118] }\end{array}$ \\
\hline
\end{tabular}




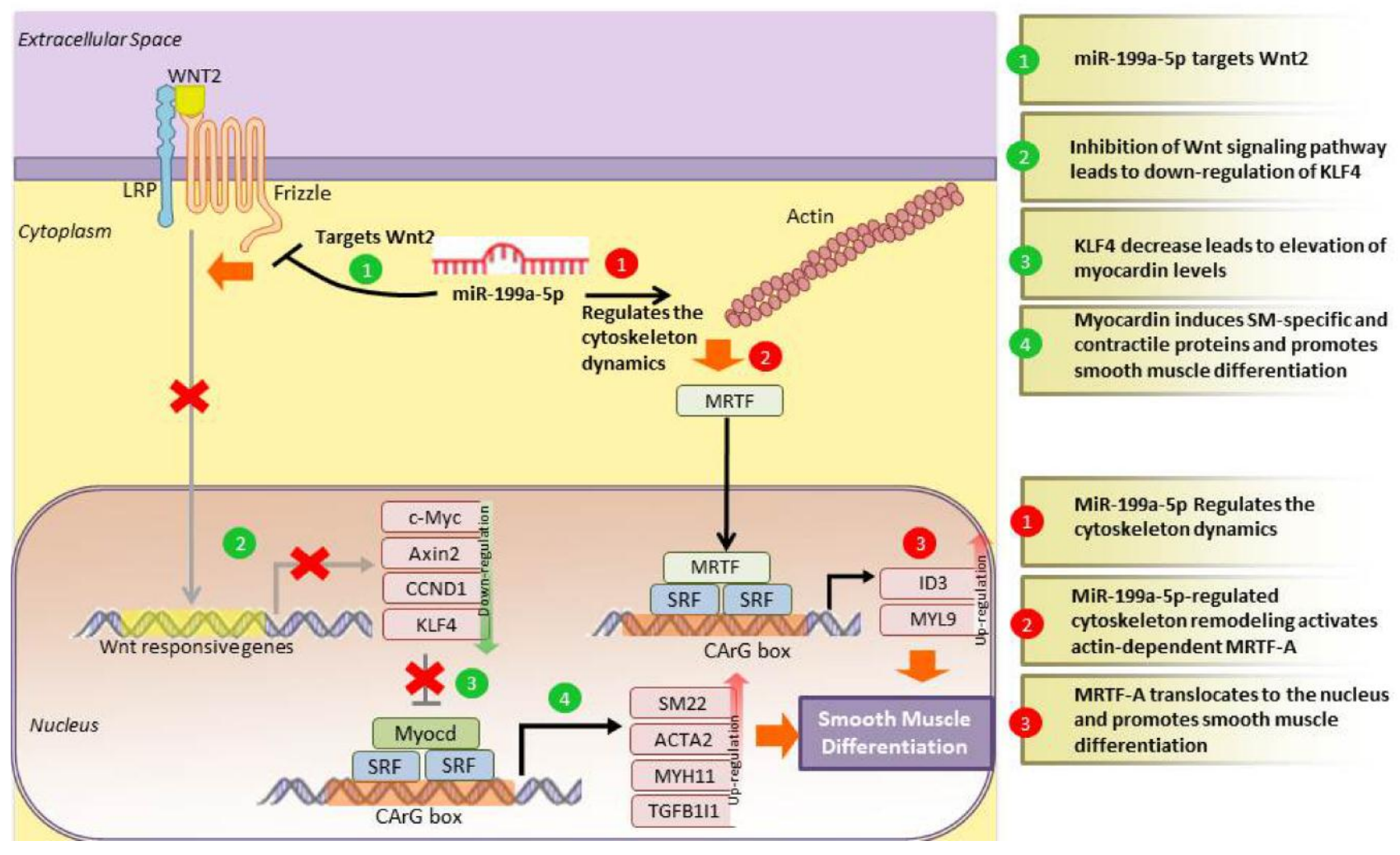




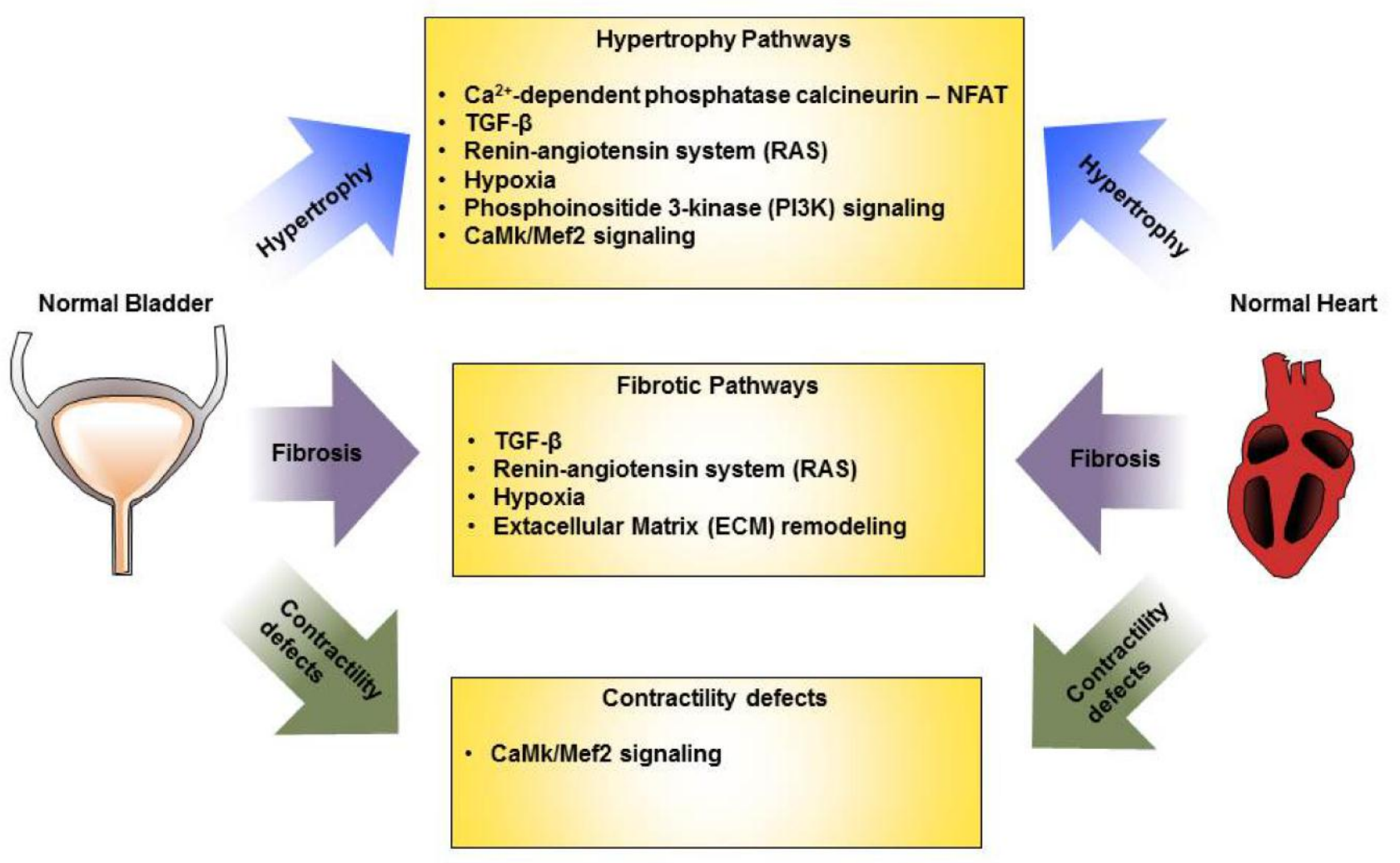




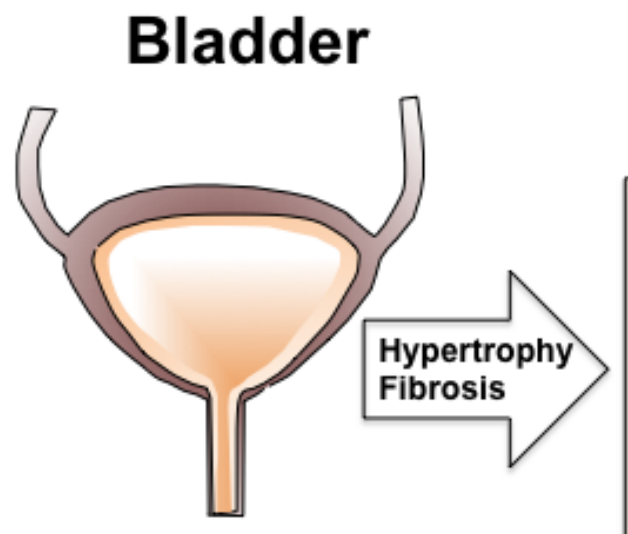

Common signaling pathways

Regulatory miRNAs

Hypertrophy

Fibrosis

Heart 